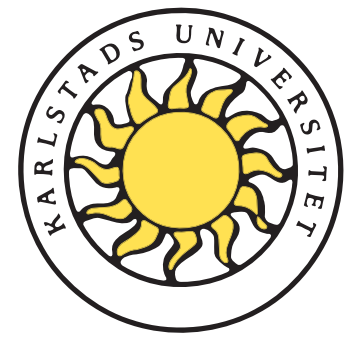

Faculty of Economic Sciences, Communication and IT CTF - Service Research Center

Samuel Petros Sebhatu

\title{
Corporate Social Responsibility for Sustainable Service Dominant Logic
}


Samuel Petros Sebhatu

\section{Corporate Social Responsibility for Sustainable Service Dominant Logic}


Samuel Petros Sebhatu. Corporate Social Responsibility for Sustainable Service Dominant Logic

\section{DISSERTATION}

Karlstad University Studies 2010:10

ISSN 1403-8099

ISBN 978-91-7063-296-9

(C) The Author

Distribution:

Faculty of Economic Sciences, Communication and IT

CTF - Service Research Center

65188 Karlstad

054-7001000

www.kau.se

Printed at: Universitetstryckeriet, Karlstad 2010 
To

My mother and late father

Who gave me everything they have 



\begin{abstract}
The process of globalization over the past five decades has given impetus to driven sustainability and related thinking in business. It is also observed that there are unprecedented trends in corporate strategy towards sustainable thinking - the emergence of sustainability as corporate strategy and the concern of business for ecology and society. This forces companies to rethink their standard business models and increase their interest in innovating products and services based on the challenges of global sustainable development. The pressure from external stakeholders, mainly non-governmental organizations (NGOs), as drivers of change may also contribute strongly to this endeavour. This substantial change pressure clearly reflects companies' recognition of the mounting pressures for social responsibility and governance. The overall aim of this thesis is to describe and understand how social responsibility and value-creation of customers' influence the overall service quality of companies in developing a sustainable service business.
\end{abstract}

The theoretical and conceptual frame of reference finds its stimulation from the research in sustainable development - corporate social responsibility, service research and quality management. In this way it attempts to bridge the gap between business and social responsibility. Theoretically and conceptually, the thesis amalgamates sustainability thinking and the service logic. Here, value creation and co-creation of Service Dominant Logic (S-D logic) approach expands to integrate the values based approach of Corporate Social Responsibility (CSR) in management thinking and have created the prevailing business practices and service quality (SQ) improvement. This thesis is a compilation of five different papers that follow an interpretative case study approach. The empirical study developed from the cases of multinational companies, small and medium enterprises, smallholders and NGOs.

In this thesis, 'Sustainable Service Dominant Logic' (SSDL) was labelled to argue that value-based co-creation of the S-D logic framework can be used to create values-based services for sustainable business by examining the link between CSR and S-D logic based on value, values and service quality for sustainable business. This is this thesis's contribution to the ongoing discussion of the paradigm shift in service research. The framework is of the integration of CSR thinking into service business to create sustainable business thinking. This signifies the new thinking of incorporating different management systems in creating the organizational change process, sustainability and finally SQ improvement. This counters the critique against S-D logic by expanding the societal and ethical dimensions by using CSR, and showing real business cases. This depends on the integration of different change pressures for value creation, whether related to economic and social resource integration. This involves the shift of the focus of managerial control from a preoccupation with financial issues to a wider awareness of CSR thinking. These issues are also explored by demonstrating, based on cases, how the adoption of this perspective can also enable the Base of the Pyramid (BoP) framework to become an important aspect of value creation. Finally, the paradigm shift can be generalized to new thinking in S-D logic and the social responsibility of businesses as the major phenomenon of the changing and globalizing business environment; time for the CSR framework to permeate S-D logic. 

My aim is not to teach the method that everyone ought to follow in order to conduct his reason well, but solely to reveal how I have tried to conduct my own.

René Descartes, in Discours de la méthode, 1637

\section{Preface}

My personal experience and an expedition starting from the Horn of Africa has not only created a deep impetus but a metaphor for this thesis. This journey began from East Africa, continued to South Africa, the coast of the Indian Ocean, Durban, and to Sweden - Miljöcentrum and Karlstad University - service research centre (CTF). I spent more than 30 months in South Africa, where I became acquainted with social responsibility thinking and research on corporate governance, codes and practices of South Africa based on the King II codes. In 2004, I received a scholarship from Miljöcentrum to study at the Service Research Centre (CTF) of Karlstad University, in the international service management research (master's) programme. This was when I had an opportunity to become acquainted with service research and the emerging paradigm of Service Dominant Logic (S-D logic), and to obtain personal experience of environmental sustainability, under the mentorship of Miljöcentrum. This helped me to gain a strong sense of ecology, environmental movements, change pressure and the contributions of external stakeholders such as non-government organizations (NGOs) and business. It was an interesting learning and transformation process for a person with a limited knowledge and experience of environment and sustainable business, and was a chance to live organically, to distinguish, assess and be inspired by the work that Dr. Björn Gillberg and Miljöcentrum had carried out for more than 35 years.

This journey of preparing a thesis on sustainable service business and corporate social responsibility (CSR) was undertaken with enthusiasm, at least to glimpse the environmental movement and with the core objective of creating a sustainable society for future generations. This way of thinking affects companies' business models in terms of the way they do business and their contributions to sustainability. I tried to assess and understand Miljöcentrum's history. For me personally, being part of this pioneering and far-sighted organization, which worked hard to transform companies into sustainable value, is a way of engendering better thinking about assessing and analysing the ethical values of organizations and how they create strategic value for their stakeholders and conduct service research.

The search for better understanding of, and learning about, sustainable business, contributions and environmental and social sustainability started with my master (MSc.) thesis about one successful case that of a paint manufacturing plant, Flügger AB, Sweden. 
This plant is one of the many companies that were reached at the verge of being closed due to negligence to environment. However, it was transformed through Miljöcentrum's know-how and advice on Environmental Management System (EMS). The master thesis also paved the way for deeper examination of the concepts of sustainable business, social responsibility and values-based service research. The engagement of Professor Bo Enquist as my advisor also extended my intention to deeply examine values-based social and ethical thinking for integrating management accounting through guidelines, standards and initiatives. This was very important to gain a sense of sustainable business and service research, and to dream of reaching new horizons.

I began to develop a thesis that demonstrates how different environmental and social standards may be proactive mechanisms for value creation of sustainable service business within the framework of service quality. This can be done by developing business cases, analysing standards and guidelines, sustainable performance measurement, and integrating these into sustainable business thinking. It can also be done by integrating the S-D logic, service quality and values-based service thinking into CSR initiatives, which is part of the ongoing research at CTF.

The CTF service research centre has not only paved the way and contributed to this study, but also has increased the thoroughness of this study. CTF (based on different projects) provided me every possible assistance and a chance to complete the journey of this thesis, besides the bump. The final year was more than reading and writing-it was a year of reflection and sharing. The centre, especially SAMOT (the Service and Market Oriented Transport Research Group) provided an opportunity, to break out of my shell and assess a wider scope of public transport. In addition to everything else, my last year's study was sponsored by CTF and SAMOT projects.

I could say that the journey has not been smooth, and took more than it possibly will. Yet it was a very interesting learning process of self-actualization and part of the larger personal metaphor of the change process. It is also a base for the beginning of another journey of shared values.

\section{Acknowledgments}

The journey is reached at a stage where I have to take a moment and look back again, to the beginning of this thesis. Miljöcentrum decided to extend funding my studies, to start the $\mathrm{Ph}$. D. program, to broaden my thinking and experiences. My journey was started with a scholarship from Miljöcentrum. Miljöcentrum sponsored the first three years of my 
studies. I extend my heartfelt gratitude to Marianne Gilberg (Msc.) and Dr. Björn Gillberg, particularly, for their invaluable contributions and mentorship. Thank you again! My thanks is also due to Georgina Koomoson, not only for your inspiring story and interviews, but also for taking your time in touring us Accra, Ghana, and your very helpful interest in my studies. I would also like to extend my thanks to Bo Forseaus and Anders Frisk in Flügger AB for the interview. Irene Backalund, Flügger, thank you very much for your cooperation in touring me the plant and your help in accessing all the necessary documents. I would also like to acknowledge Gunnar Rundgren and Kari Örjavik of Grolink $\mathrm{AB}$ for allowed me to attend the Organic Agriculture Development (OAD) training, interviews and cooperation. As well, the participants of the OAD from all over Africa thank you for your inputs. Thank you, Tommy Kullberg and Thomas Bergmark, from IKEA, Mondrup, J. of Löfbergs Lila and Lars Svensson of Jehander for the meetings and interviews.

I would like to genuinely thank my main advisor Professor Bo Enquist, who has immensely contributed towards the successful completion of this thesis. His encouragement to begin with, his suggestions, criticism, and perceptive advice were all invaluable throughout this thesis. You were always there to compassionately sharing your deep knowledge and experience with me. Your mentorship was invaluable, but not limited to only academic guidance, also life experience. He was there any time I needed his assistance and guidance. Associate Professor Hilde Ibsen has also been my advisor from day one. You have not only been of great support. You have always been there to share whatever you know and have. Hilde is very knowledgeable and compassionate in sustainable development thinking, and the research methodology. Your input made a difference. Dr. Mikael Johnson, I was glad when you became my advisor. His knowledge and his thoughtful remarks and advice have significantly enhanced the quality of this thesis, especially at the end of this journey.

Being a doctoral student to be at Karlstad University, and Service Research Center - CTF is not only as good as being in other universities or centers, in respect to my experience. It is a real pleasure and privilege for me to be a member of this research community. I have realized that being a member of this community is a life time opportunity. This is also goes to Service and Market Oriented Transport Research Group-SAMOT group. I had the good riches to become a member of a multidisciplinary research group. Thanks to Bo Edvardsson, Patrick Larsson and to all of my colleagues at CTF. Margareta Friman and the SAMOT management thank you for believing in me and extend your support. Thanks Anders Gustafsson and Martin Löfgren for showing interest in my research and including me in your research project. I am proud of being member of CTF and SAMOT. 
I am thankful to Berit Hjort, the diligent librarian, for your help in reassessing my reference and lasting ideal support. Thank you very much Katarina who designed the models of the $2^{\text {nd }}$ and $5^{\text {th }}$ chapter and redesigned all the figures in this thesis. Thanks to Jörg too for your vigilant reading of my manuscript.

My thanks' also extends to Katarina E. and Thomas, Erik S., and Katarina, Pernilla and Anders Gillberg and your families for your friendship. Anki, Makosi and your family, thanks for always being there. I appreciate and value your friendship very much. Gunilla, Lars-Gunnar Johnson and your family, thank you for the good times and your help. I couldn't pass without special heartfelt thanks to Rosita E., Bo-Jacob E. and Sara for making feel us part of your family and everything that comes with it. Bo-Jacob, we had a very good discussion on different issues and being to interviews together. You made a very good contribution to this thesis.

My family, Mother and (father), you gave me more than you had. I don't have words to put it here. Father, I believe that you are always live among us and share this gratitude. My sisters and brothers wanted me to fulfill my dream and always being there for me. I could say a lot to articulate my feelings, for which we shared a lot. But I will only eloquently say I love you and Thank you for everything! It is also extend to my another family Mengisteab (Bashay), Freweini, and your family thank you for always being there - Kibret Yihabeley. Long time friends, ENDABA, you know who you are, thank you for your continuous care and tirelessly encouragement. To all of you, I remain honestly appreciative.

Now, I will take my turn. My lovely wife, Eden, I always value and love you for whom you are! Thank You for your unconditional love and for always being on my side. It couldn't be unthinkable without you. Miriam and Magda, you are such a source of joy and happiness. Thank you, Edu for our lovely daughters. Edu, Mimmi and Magdis, Thank you for your patience, love and care.

Last but, of course, not least, I thank the Heavenly Father for His omnipotence that made this journey, with its ups and downs, a reality.

Karlstad, March - 2010 


\section{TABLE OF CONTENTS}

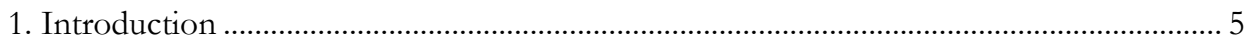

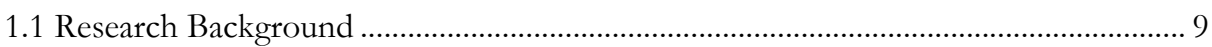

1.1.1 Corporate Social Responsibility (CSR) …….......................................................... 10

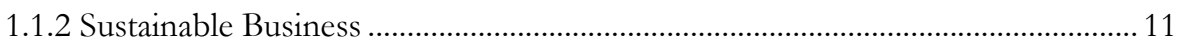

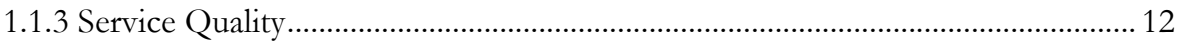

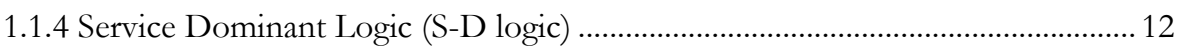

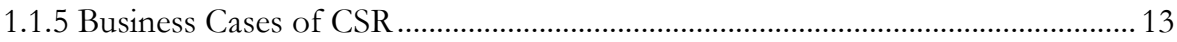

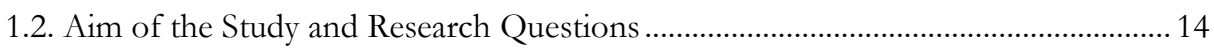

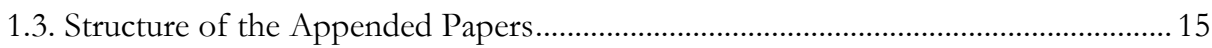

1.4. Summary of the Appended Papers .............................................................................. 16

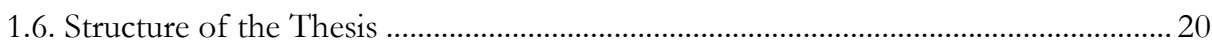

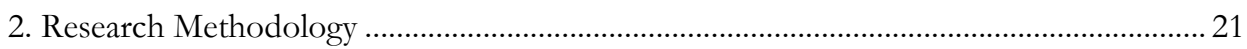

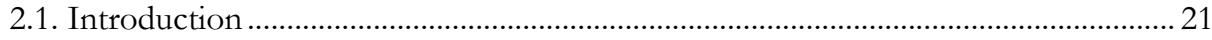

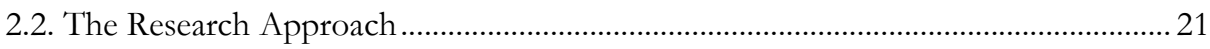

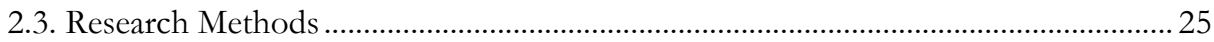

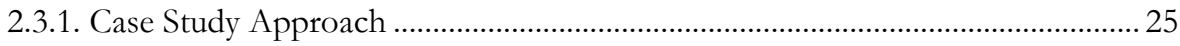

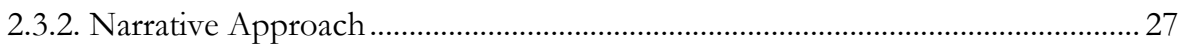

2.3.3. Source Material Collection................................................................................... 28

2.3.4. Source Material Collection Process of the Appended Papers............................... 30

2.4. Trustworthiness_-Reflections of the Research Methodologies and Design ............ 35

3. Theoretical and Conceptual Framework ………................................................................. 37

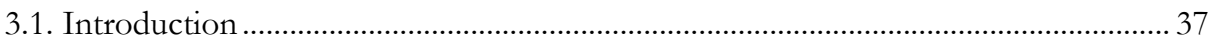

Business and the Necessity for Values ........................................................................ 37

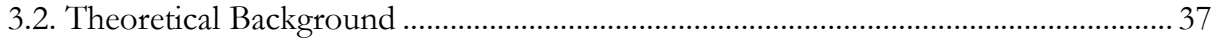

3.2.1. Pressure to Change as it Relates to Corporate Responsibility ............................. 39

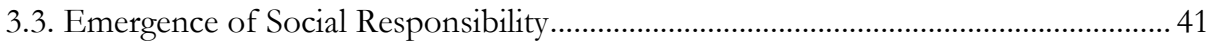

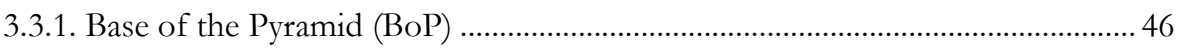

3.4. Service Quality Orientation for sustainable business ................................................ 47

3.4.1. Shared values for Service Business ......................................................................... 49

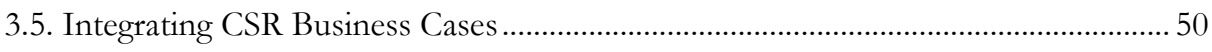

4. Contributions of the Appended Papers ............................................................................. 53

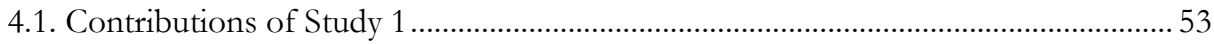

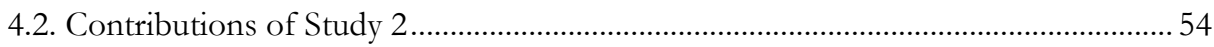




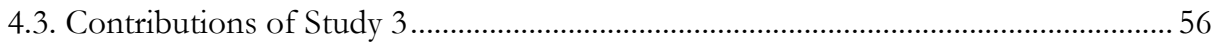

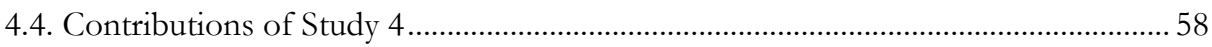

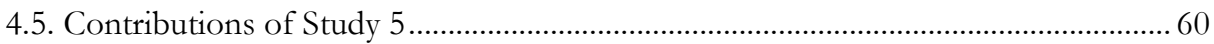

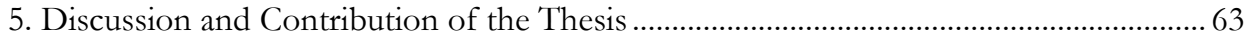

5.1. Role of CSR in Sustainable Value Creation and Improvement of Service Quality. 63

5.2. CSR Values for S-D logic of Sustainable Service Business ....................................... 65

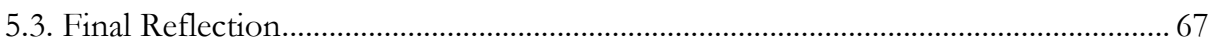

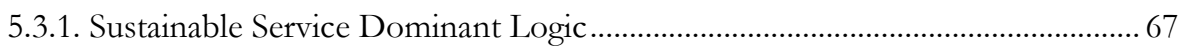

5.3.2. Sustainable Service Business - The Future .......................................................... 71

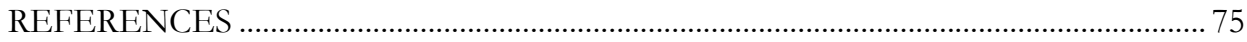

\section{Figures}

Figure 1: The use of business cases for sustainability for creating relations of the concepts 9

Figure 2: The framework of the appended papers $\quad 15$

Figure 3: The hermeneutic circle basic version $\quad 24$

Figure 4: Model of the interrelationship of the chapters and chapter two 36

Figure 5: A model of values-based service quality for sustainable service business $\quad 55$

Figure 6: The proposed model for analysing change process 59

$\begin{array}{ll}\text { Figure 7: The SSDL business case model } & 68\end{array}$

Figure 8: Understanding SSDL through business cases $\quad 70$

\section{Tables}

Table 1: Summary of the appended papers 22

Table 2: The historical and most common definitions of CSR 43 


\section{List of Abbreviations}

BCSD Business Council for Sustainable Development

BoP Base of the Pyramid

CSR Corporate Social Responsibility

CTF Centrum för tjänsteforskning

EMAS Eco Management and Audit Scheme

EMS Environmental Management System

EU European Union

G-D Logic Good Dominant logic

ICC International Chamber of Commerce

ISO International Organization for Standardization

MNCs Multi-National Company (ies)

NGOs Non Governmental Organization(s)

SAMOT Service and Market Oriented Transport

SB Sustainable Business

SD Sustainable Development

S-D logic Service Dominant logic

SQ Service quality

SR Social Responsibility

SPM Sustainability Performance Measurements

SSB Sustainable Service Business

SSDL Sustainable Service Dominant logic

TBL Triple Bottom Line

TQM Total Quality Management

UNCED United Nations Conference on Environment and Development

VOC Volatile Organic Compound

VBSQ Values Based Service Quality

WBCSD World Business Council for Sustainable Development

WCED World Commission on Environment Development

WWF World Wildlife Fund 


\section{APPENDED PAPERS}

\section{Paper 1}

Sebhatu, Samuel P. and Enquist B., (2007), 'ISO 14001 as a driving force for Sustainable Development and Value Creation', The TQM Magazine, Vol. 19, No. 5, pp. 468-482.

\section{Paper 2}

Enquist, B., Edvardsson, B. and Sebhatu, Samuel P., (2007), 'Values-based Service Quality for Sustainable Business', Managing Service Quality, Vol. 17 No. 4, pp.385-403.

\section{Paper 3}

Enquist, B., Edvardsson, B. and Sebhatu, Samuel P., (2008), 'Corporate Social Responsibility for Charity or for Service Business?', The Asian journal on Quality, Vol. 9 No. 1, pp.55-67.

\section{Paper 4}

Sebhatu, Samuel P., (2010), 'The Role of Change Agents for creating Sustainable Business and Responsible Management - Case study of Miljöcentrum', Preliminary version-Presented at the $12^{\text {th }}$ QMOD and ICQSS conference, Verona, Italy (August, 2009).

\section{Paper 5}

Sebhatu, Samuel P., (2008), 'The Challenges and Opportunities in creating Sustainable Shared Values at the Base of the Pyramid - Cases from subSaharan Africa', Kandachar Prabhu and Minna Halme (Editors) "Sustainability Challenges and Solutions at the Base-of-the-Pyramid: Business, Technology and the Poor", Green Leaf Publishing, Sheffield, UK, pp.146-162. 
"Man ought to regard himself, not as something separated and detached, but as a citizen of the world, a member of the vast commonwealth of nature and to the interest of this great community, he ought at all times to be willing that his own little interest should be sacrificed." Adam Smith, Theory of Moral Sentiments (1790, p.140)

\section{Introduction}

The evolving paradigm shift in management thinking is influenced by the extensive scope and ever-increasing demands of customers and stakeholders (Enquist et al., 2006). The changing needs of stakeholders, technological development and economic pressures contribute to the need for organizations to change significantly the ways in which they think and act (Brown and Eisenhardt, 1998). It is also observed that there are unprecedented trends in corporate strategy towards sustainable thinking - the emergence of sustainability as corporate strategy and the concern of business for ecology and society. Vogel (2005) in his book has described the shift towards a sustainable business as a move from "Doing Good to Do Good" for green washing or corporate philanthropy to "Doing Good to Do Well" strategic decisions, which he has contrasted with a new understanding of Corporate Social Responsibility (CSR). Business organizations are expected to adopt values-based thinking and practise ethical behaviour and responsible management in order to change conspicuously and quite abruptly their form and structure. This forces companies to rethink their standard business models and increase their interest in innovating products and services based on the challenges of global sustainable development. This is based on the corporate social responsibility approach or way of thinking, for efficiency in quality (Pruzan, 1998; Gummesson, 2006; 2008; Edvardsson and Enquist, 2009; Edvardsson et al., 2006; Enquist et al., 2006). This approach is also cautious and assists companies to respond to early signs of important social shifts and consumer interest as they search for new and better ways to create value and differentiate their market offerings to attract and retain customers and make a profit (Shaw and Ivens, 2002). It is my objective in this thesis to describe and understand ethical value creation, shared values and governance of companies. 
The recent discourse of Service-Dominant logic (S-D logic) and value creation (Vargo and Lusch 2004; 2008; Lusch and Vargo, 2006) also portrays the contemporary shift in management thinking. S-D logic describes the paradigm shift from the goods-dominant logic (G-D logic) of neoclassical economics thinking to the S-D logic thinking about the application of competences (knowledge and skills). This represents a shift from thinking about value in terms of making resources valuable by positioning the customer on the same "level" as the firm (Vargo and Lusch 2004; 2008; Lusch and Vargo, 2006). The authors of the S-D logic endeavoured to shift the dominant productorientated management paradigm towards service-orientated value creation, which was primarily the study of firms' perspectives on exchange of goods. However, S-D logic does not include the seriousness of global sustainability and challenges to business that lead to major strategic decisions and new business models. It takes no notice of the increasing awareness that incremental solutions will be insufficient to maintain critical levels of environmental and social outcomes. The insights from sustainable business practice provide opportunities to reshape strategies for competitive advantage, quality and values-based thinking (Edvardsson and Enquist, 2009; Enquist et al., 2008; Gummesson, 2006; 2008). Value creation for customers (S-D logic) by businesses based on social and environmental values are in accordance with the shared values of customers and other stakeholders (Edvardsson and Enquist, 2009). Therefore, the conceptual framework for a paradigm shift can be generalized to new thinking in Service-Dominant logic ( $S-D$ logic) and social responsibility of business as the major phenomenon of the changing business environment and globalization.

A values-based business is thus based on a combination of core company values and foundational values that guide a company in creating customer value and a sustainable service business (Enquist et al., 2008; Edvardsson and Enquist, 2009). Organizations' values concerning their stakeholders are always likely to be not only bases of exclusion or inclusion depending on their contributions to value creation and sustainability, but also as shifts in thinking and strategy. Although the authors (Vargo and Lusch, 2008; Lusch and Vargo, 2006) have mentioned that S-D logic provides a framework for understanding how business and the process of value creation fosters sustainability and stakeholder thinking, it is focused only on economic value related to resources, ignoring the customer life cycle and total cost of ownership. This approach was noted by researchers who urged for greater focus on societal and ethical dimensions (Laczniak, 2006; Gummesson 2006; Abela and Murphy, 2008), which was later accepted and recommended as a significant research 
opportunity combining these concepts with value creation for customers (Lusch 2007; Vargo and Lusch 2008a; 2008b). Yet comparatively little attention has been devoted by scholars and practitioners to the important role played by values in creating value for customers and other stakeholders (Edvardsson and Enquist, 2009). As argued by several researchers (Edvardsson and Enquist, 2009; Enquist et al., 2008; Abela and Murphy, 2008; Gummesson, 2006), what is missing is a holistic view of making sustainable development an integral part of a company's business strategy to obtain bottom-line benefits and create value for the stakeholders. Pruzan (1998) introduces values-based thinking of management and argues that this phenomenon is not new. He criticizes traditional shareholder accountability based specifically on the financial bottom line (ibid.). There has been a tendency to transform all the relevant information into this unit to make complex management decisions easier (Edvardsson and Enquist, 2009; Vargo and Lusch 2008).

In this thesis, I label "Sustainable Service-Dominant Logic" (SSDL) as the basis for the argument that value-based co-creation of the S-D logic framework can be used to create values-based services for sustainable business by examining the link between CSR and S-D logic based on value, values and service quality for sustainable business. This is the contribution of this thesis to the ongoing discussion on the paradigm shift in service research.

The development of the involvement of companies and the emergence of sustainability thinking in business can be seen together as a proactive driving force (Edvardsson and Enquist, 2009). Companies of any size mostly focus on growth as a developmental process. This process of growth of companies always prioritizes maximizing profits to create value for their shareholders and this is neoclassical economic thought from a G-D logic perspective (Gummesson, 2006; Vargo and Lusch 2004; 2008). However, it is not my intention to study business growth; the development process or movement of companies towards sustainability is related to their strategies of efficiency, augmentation and differentiation, or competitive advantage.

This can be assessed and analysed through CSR business cases on an empirical basis and is discussed in the appended papers. The first stage of sustainable business is to escape from single bottom-line thinking about profitability, which is shifted from a single focus on shareholder value (Friedman, 1962) to incorporating stakeholder thinking to create value and sustainable competitive 
advantage (Enquist et al., 2006). This has been described by many researchers and economists since Adam Smith, and is argued in S-D logic (Vargo and Lusch 2004; Lusch and Vargo, 2006; 2008). In the new economy and in the transformation of thought to values-based thinking (Edvardsson and Enquist, 2009; Edvardsson et al., 2006; Enquist et al., 2006), sustainable development is not only a new management challenge to achieve efficiency (quality). It also extends beyond the short-term profit focus (Gummesson, 1994; 2006) to become "an institution of social control instrumental in reorienting a culture from a producer's to a consumer's culture" (Edvardsson and Enquist, 2009, pp. 37-8).

The commitment of sustainable companies is to create shared value for stakeholders. Edvardsson and Enquist (2009) argued that creating sustainable value is a way for companies to advance their business priorities, achieve competitive advantage and drive innovation. Doing so in today's competitive context requires leading companies to consider carefully the social and environmental dimensions of their business activities (Laszlo, 2008) and value creation. This can be achieved by integrating "societal" stakeholders such as NGOs and citizens as potential business partners rather than as illegitimate adversaries (Waddock, 2008). In recent years, NGOs have assumed an increasingly important role in society as drivers of change and have contributed to shaping the demands of market externalities and consumers (Edvardsson and Enquist, 2006), and have come to influence corporate life (Teegen et al. 2004; Sjostrom, 2008). In fact, they can be defined as coalescing around common ideas, needs, or causes; and as collectively mobilizing their common interests. Several NGOs have raised awareness of issues related to corporate behaviour and social responsibility. This deepens the corporate responsibility strategy (Edvardsson and Enquist, 2009), by which a company's strategies and operating practices have an impact on their values, society, stakeholders and the natural environment (Waddock, 2008). Substantial change also clearly reflects companies' recognition of the mounting pressures for value creation based on long-term profits, social responsibility and governance (Gummesson 2006; Waddock, 2008).

This thesis will make a holistic contribution to assessing business views for SSDL based on CSR for ethical, economical, ecological and social sustainability. I argue for a shift from image to value creation for both shareholders and stakeholders. 


\subsection{Research Background}

The search for previous studies on sustainable development and sustainable service in business focused on CSR, Sustainable Business (SB), S-D logic and Service Quality (SQ) based on business cases for SSDL, as indicated in Fig. 1. The main concept of this paper - CSR - for instance, is similar to other important concepts such as democracy and justice and is "essentially contested" (Moon, 2002). From a survey of CSR education in Europe, Wayne Visser (2006) found 50 labels for CSR modules, 40 labels for CSR programmes and numerous CSR synonyms. Moreover, since 2006, more than half of the master of business administration curricula in the United States requires students to take at least one course on the subject (Reich, 2008). The terms CSR and Sustainable Development are used differently in various databases as they are applied to multidisciplinary subjects in varying contexts. S-D logic also as a new and emerging concept in the literature began in 2004 after the first article by Vargo and Lusch (2004). The main focus of the literature review was to assess and examine almost all publications on S-D logic between the years 2004 and 2009. Therefore, my search mainly focused on business management thinking in the databases of business, economics and social sciences. I mostly examined library databases, books and journals including LIBRIS. This helped me to obtain quality and balanced information and to avoid irrelevant source material. I used Emerald, Business Source Premier, EBSCO, Academic Search Elite, Google Scholar, and ISI. In general, the strategy was to focus on how information is generated, stored and retrieved (Hart, C. 2001; Gummesson, 2000).

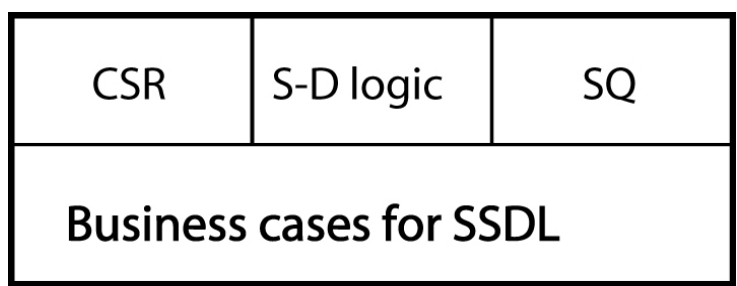

Figure 1: The use of business cases for sustainability for creating relations of the concepts

At the beginning, the information search process focused solely on identifying the available literature and gathering as much information as possible, because 
information on the subject is so limited. For instance, in Emerald I obtained 42,680 results/hits for service quality in all fields, and 298 results/hits for ISO 14001 in all fields. However, I found only 193 results/hits in all fields for combined service quality and ISO 14001. Similarly, for S-D logic, I obtained 63 in all fields in EBSCO and 53 results/hits in Emerald, and none for S-D logic combined with sustainable development or sustainable business except a single publication on S-D logic and ethics by Abela and Murphy (2008).

The search also included new information, in order to get additional knowledge within this area, and assess the research gap. At later stages in the course of the study, I again searched for information to legitimize the information presented. In addition, as Grisvold (1999) suggests about the relation between citation and quality of an article, I devoted enough time to identify the most commonly cited articles and publications in the database. These phases facilitate the process by limiting the research focus and identifying the relevant information available in this study area.

\subsubsection{Corporate Social Responsibility (CSR)}

The term corporate social responsibility today is one of the most widely used concepts in business (Vogel, 2005; Enquist et al., 2008). CSR was first used and defined by Bowen (1953), but the debate over the responsibilities of business for ecology (environment), and its relationships with the society has continued. There is still no consensus on a definition of CSR (Prieto-Carrón, et al., 2006; Vogel, 2005; McWilliams and Siegel, 2001; Jones, 1995; 1999; Carroll, 1991). Waddock (2004) tries to explain the dilemma by cataloguing the terminology and ideas. This wide debate raises the questions regarding both the role of business and the significance of companies' internal structures and contents to the general population (Sethi, 1975, p. 58).

Prieto-Carrón et al. (2006, p. 978) proposed the following broad definition of CSR:

... an umbrella term for a variety of theories and practices, all of which recognize the following:

(a) that companies have a responsibility for their impact on society and the natural environment, sometimes beyond legal compliance and 
the liability of individuals; (b) that companies have a responsibility for the behaviour of others with whom they do business (e.g. within supply chains); and that (c) business needs to manage its relationship with wider society, whether for reasons of commercial viability, or to add value to society.

The above definition is broad and integrates different views of CSR. It is mainly defined as concepts and strategies by which companies voluntarily integrate social and environmental concerns into their business operations and stakeholder interactions (Enquist et al., 2006; 2008). In other words, CSR is the concept that an organization is accountable for its impact on all relevant stakeholders.

\subsubsection{Sustainable Business}

Sustainable Business (SB) in business management is related to the commonly used concept of sustainable development, a socio-political concept, which is part of stakeholder thinking. Sustainable business as a concept of sustainable development has long been decried for lacking a strong definition of business. The word sustainability even implies a presumption of no economic development (Ehrenfeld, 2005). The World Business Council on Sustainable Development (WBCSD), however, extends the definition of sustainable development in "Our Common Future" (1987) to "Sustainable development involves the simultaneous pursuit of economic prosperity, environmental quality and social equity. Companies aiming for sustainability need to perform not against a single, financial bottom line but against the triple bottom line" (WBCSD, 2004, p. 1). The essence of this form of development is a stable relationship between business activities and the natural world, which does not diminish the prospects for future generations to enjoy a quality of life at least as good as this generation (Mintzer, 1992). It is also a way to a new view of corporations for what they are, what they do and how they relate to social environmental and political concerns in a manner previously unthinkable (Demirag et al., 2005, p. 356). 


\subsubsection{Service Quality}

A common definition of service quality is that service should correspond to the customers' expectations and satisfies their needs and requirements (Edvardsson, 1998). The definition is customer orientated. To detect and understand non-verbalized customer needs, a sense of insight, a functional dialogue with the customer and an understanding of his or her situation are required (ibid.; Grönroos, 1984; Parasuraman et al., 1988; Gummesson, 1994; 2008). Service quality is linked to activities, interactions, and solutions to customer problems. One of the main advantages of integrating service quality (Schneider and White, 2004) as part of developing processes is creation of value in terms of quality and organizational sustainability (Gummesson, 1994; Enquist et al., 2007). Schneider and White (2004) opened the way for new research areas by discussing the emergence of integrating total quality management (TQM) and other service offerings into operations management. Enquist et al. (2007) assessed the contributions of service quality to sustainability and contributed to values-based service quality thinking by integrating it with other concepts such as TQM (Sebhatu and Enquist, 2007; Edvardsson and Enquist, 2009). This represents the new thinking of incorporating different management systems into the creation of service quality delivery (Enquist et al., 2008; Schneider and White, 2004).

The term green service quality was coined in 1994 (Gummesson, 1994). It reflects the necessity for, and urgency of, sustainable service quality thinking. However, Gummesson (1994) describes his revelations on green marketing and quality as: "It is astonishing how late this reaction has come; marketing people usually flatter themselves as being sensitive to market signals, even to weak signals" (ibid., p. 33). There are very few studies based on this concept, besides Bergström and Gummesson's (1995) article on the environmental aspects of service quality.

\subsubsection{Service Dominant Logic (S-D logic)}

Value creation and co-creation is a central principle of S-D logic: "A servicecentred dominant logic implies that value is defined by and co-created with the customer rather than embedded in output" (Vargo and Lusch 2004, p. 6). Service is also defined as the application of operant resources of knowledge 
and skill for doing something as part of an exchange process. It is the cocreation of value through resource integration (ibid; Vargo and Lusch, 2008b). Value is co-created by both a firm and a customer: (at least) two actors. Valuein-use is realized for the customer at the time a service becomes real in action (Vargo and Lusch, 2004; Edvardsson et al., 2005). The construct of S-D logic remains resource-centred, which is grounded in Resource-Advantage theory (Hunt 2000; Vargo and Lusch 2004; Lusch and Vargo, 2006).

S-D logic is a constructive frame for theory building (as opposed to a normative framework), based on ten "foundational premises" (FPs) (originally eight in the prior publication), as argued by various authors (Vargo and Lusch, 2004; Vargo and Lusch, 2008b). However, S-D logic has no broad and explicit perspective of societal value creation except one FP (9) indicating that social and economic actors are resource integrators, which is a positive (nonnormative) assertion by Vargo and Lusch (2008a). As a value creation process that is essentially relational, S-D logic mostly concerns economics (seven of the FPs, except FPs 6 and 9). Abela and Murphy (2008) concluded that the FPs do not have an explicit ethical content. This is argued from a variety of viewpoints, such as relationship marketing and quality (Gummesson, 2006; 2007a; 2008), social responsibility (Enquist et al., 2008), values-based thinking (Edvardsson et al., 2006; Edvardsson and Enquist, 2009) and marketing ethics (Abela and Murphy, 2008). The integration of sustainability and stakeholder thinking for social responsibility and decision-making allows S-D logic to have a broader view and reflect its implicit assumptions regarding business ethics. It also represents a shift from static to dynamic resources with a stakeholder rather than a customer-centric perspective (such as those of employees, valuecreation partners, and customers) (Edvardsson and Enquist, 2009).

This shift in thinking towards sustainability by integrating CSR with S-D logic thinking for shared values for quality service is the basis of a sustainable service business. This can be analysed through business cases.

\subsubsection{Business Cases of CSR}

Enquist et al. (2008) and Edvardsson and Enquist (2009) argue the importance of CSR business cases in service research on value creation in order to provide a full picture and understanding. For researching sustainable development, the choice of criteria has to be governed by values (Enquist Edvardsson and 
Sebhatu, 2008; Edvardsson and Enquist, 2009) and implemented through quality (Gummesson, 2000; 2006). S-D logic, CSR, and SQ are interrelated concepts of value creation as common ground for sustainable business. As sustainability not only translates into being "environmentally friendly", it also is broader than being efficient and operating beyond compliance (Sebhatu and Enquist, 2006). However, recent CSR practitioners have been mainly interested in the economic justification for establishing and communicating CSR business cases, signifying that financial gains could result from socially responsible activities concentrating on the creation of markets - the "markets of virtue" (Vogel, 2005).

The generally accepted norm for corporate sustainability constitutes a firm's efficient application of natural resources or eco-efficiency for value creation of its stakeholders. Eco-efficiency can be simply analysed based on organizations' strategy and commitment to sustainability, but this does not reflect efficiency in terms of integrated quality. In other terms CSR, S-D logic, and SQ are interrelated concepts that can be analysed as interrelated means for organizations to achieve sustainability. This can be achieved through developing and analysing business cases (as indicated in Fig. 1).

\subsection{Aim of the Study and Research Questions}

The main aim of this thesis is to describe and understand how CSR values and S-D logic influence service quality for developing a sustainable service business.

To achieve the aim of this thesis, the following two research questions are considered.

1. What is the role of CSR in sustainable value creation and improvement of service quality?

2. How do CSR values influence the S-D logic for developing a sustainable service business? 


\subsection{Structure of the Appended Papers}

The five appended papers in this thesis are structured as follows.

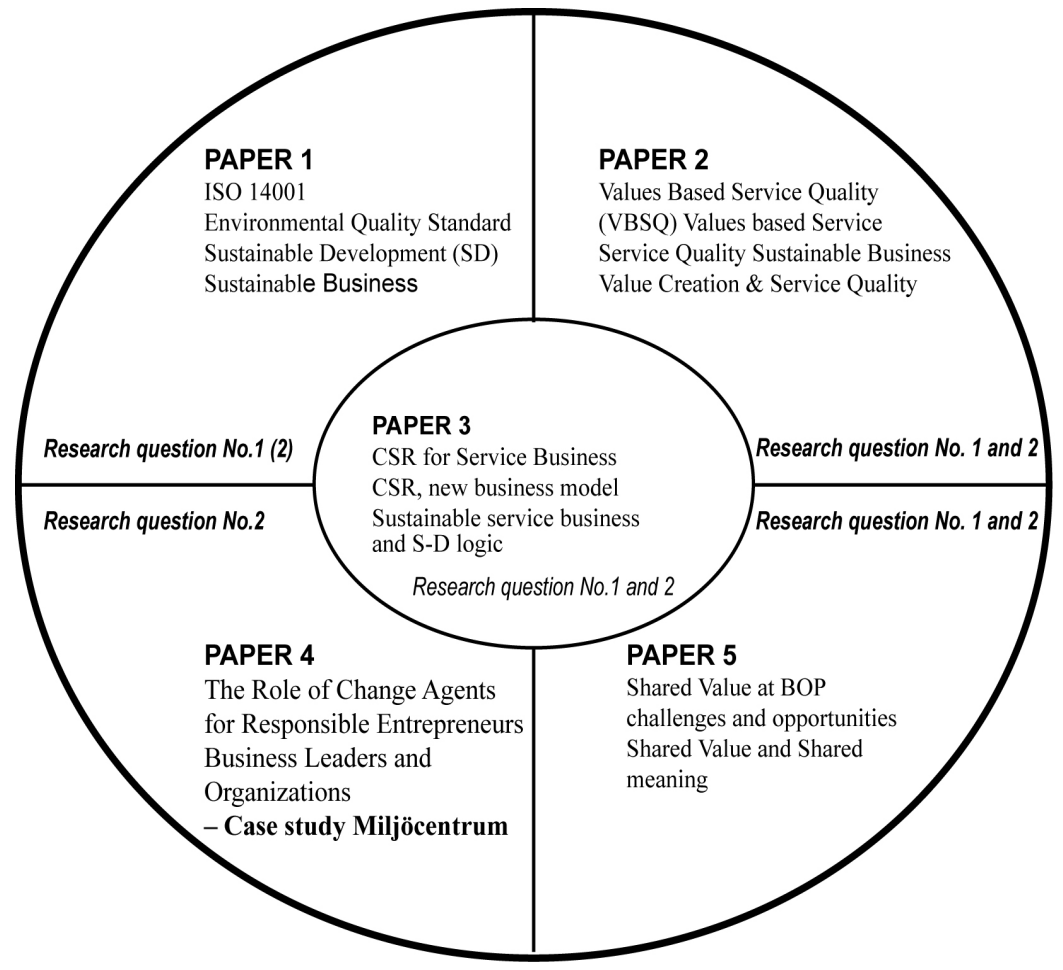

Figure 2: The framework of the appended papers

The above framework of the appended papers is designed to reflect the interconnection of the papers and their contribution to the thesis. The numbering does not reflect publication date or priority, but integration and relationships based on value creation, transformation to sustainable business, change process and the pressure to create value for the stakeholders for Sustainable Service Business (SSB). Paper 1 discusses SD and SQ; paper 2 VBSQ, CSR and S-D logic; Paper 3, CSR based on S-D logic framework and empirical business cases; Paper 4, the contribution of external stakeholders and the pressure to change to sustainable business; Paper 5, Shared value creation at the BOP based on cases. These papers are summarized in the next section. 


\subsection{Summary of the Appended Papers}

Paper 1: Sebhatu, Samuel P., and Enquist B., "ISO 14001 as a driving force for Sustainable Development and Value Creation", The TQM Magazine, Vol. 19, No. 5 (August 2007).

This paper was developed and covered in detail as a part of the master's thesis of the first author with advice from the second author. The paper was published in The TQM magazine, 2007. The paper focuses on examining whether the process of organizational change in implementing the environmental quality standard ISO 14001, can act as a driving force for sustainable development (SD) and value creation. It is based on the case study of Flügger AB.

The paper discusses the success of Flügger from the perspective of sustainability and value creation, and Flügger's commitment to the ISO 14001 process. It also assesses the question of whether this success was a result of the ISO 14001 process or other factors in this particular case. The Flügger case integrates ISO certification, TQM processes, service operations and service quality. There has been a comprehensive shift of thinking in analysing and integrating environmental and quality management by incorporating them into sustainability thinking.

In this paper, we argue that although many organizations have claimed competitive and market advantages because of implementing these standards and systems (Zutshi and shoal, 2003), the Flügger case indicates that success requires external and internal perspectives to be complementary. A successful organizational change process requires values-based service thinking (Edvardsson et al., 2006) in which ISO certification forms part of a more comprehensive quality change process, including TQM and service quality based on the same core values.

Paper 2: Enquist, B., Edvardsson, B., and Sebhatu, Samuel P., "Values-based Service Quality for sustainable business", Managing Service Quality, Vol. 17, No. 4 (July 2007).

The first version of this paper was presented at the ninth QMOD conference in Liverpool, United Kingdom, in August 2006. Enquist and Edvardsson are the main authors of this paper because this paper is developed from the first 
paper of Edvardsson, Enquist and Hay (2006) with new findings and insights on sustainable values-based service quality. Sebhatu, Samuel is the third author of this paper and contributed to the development of the five narratives, the service quality concept and the development and interpretation of the models.

This paper explores the relationships among the concepts of values-based service, service quality and sustainability. The study is premised on a stakeholder perspective of leadership, responsibility, and ethics (Pruzan, 1998), incorporating Elkington's (1997) concept of a "triple bottom line" (economic, social, and environmental) for sustainable development. Drawing on narratives from the world's leading furniture firm, IKEA, the aim of this paper is to present a model of values-based sustainable service business grounded in the concept of values-based service quality.

We argue that the service culture in IKEA is of a special character, a culture for sustainable business embedded in the company's history. That is a major reason why we have chosen the case of IKEA for our empirical study. The paper presents five narratives from IKEA. The analysis of the five narratives suggests that values-based service quality has four dimensions: "technical", "functional", "experiential", and "HRM and corporate climate". Values-based thinking can also drive sustainable development according to Kemp's (2005) five dimensions of sustainability (ethical, social, "nature-philosophic", economic, and legal), as identified in the narratives. The generalization of this study, based on the findings, can be applied to other but not all firms.

Paper 3: Enquist, B., Edvardsson, B., and Sebhatu, Samuel P., "Corporate Social Responsibility for Charity or for Service Business?”, The Asian journal on Quality, Vol. 9, No. 1 (2008).

This paper was presented at the tenth QMOD conference in Helsingborg, Sweden, July 2007. The paper was awarded best paper at this conference. Enquist and Edvardsson are the first and second authors of this paper, because it is part of their ongoing research on values-based service thinking. Sebhatu, Samuel is the third author of this paper and contributed to the development of the cases for assessing CSR as part of a service business model based on Johnston and Clark (2001). 
This paper is the first study in service research to focus specifically on CSR, which combines CSR and service logic. The present study explores these issues by demonstrating how the adoption of a "stakeholder perspective" can integrate CSR with S-D logic and thus become an important aspect of value creation and value-in-use (Enquist et al., 2006). It explores how CSR can be utilized as a strategy for innovative service business.

We present a conceptual framework for analysis of CSR and its relationship to a successful business model. The paper then undertakes a comparative qualitative study of four well-known global firms, with particular emphasis on their various CSR activities and their incorporation into the successful business models of each company. The companies examined are IKEA, Starbucks, H\&M, and The Body Shop. The paper then draws its findings together in a discussion of how CSR can be a proactive driver of innovative and successful service business, based on nine "success drivers" of service innovations in Berry et al. (2006). These nine drivers can conveniently be used to assess the CSR business cases examined in the present study, with a view to establishing whether CSR drives successful, innovative businesses. Based on this study we argue that there is no single formula for the utilization of CSR in a business model, rather, individual companies should develop their own CSR cultures and strategies to become successful.

Paper 4: Sebhatu, Samuel Petros, "The Role of Change Agents in creating Sustainable Business and Responsible Management-Case Study of Miljöcentrum" Preliminary version presented at the $12^{\text {th }}$ QMOD and ICQSS conference, Verona, Italy (August, 2009), (February, 2010).

This paper was submitted and presented at the twelfth QMOD conference in Verona, Italy, in August 2009. The aim of the paper is to assess the role of NGOs as change agents for creating sustainable business and responsible entrepreneurs and leaders. The paper focuses on analysing the case of a change agent - a Swedish environmental NGO-Stiftelsen Miljöcentrum. The case investigates the work that Miljöcentrum has performed for more than 35 years. It has three mini-cases about pressure for change and the organizational change process. The mini-cases reflect the application of different strategies for change pressure and processes that Miljöcentrum has adopted over the years. They are studies of BT Kemi, Öresund Bridge and Flügger AB. 
The paper discusses the achievements of Miljöcentrum in creating pressure for change, which can reshape strategies for competitive advantage and growth, which is practised by proactive companies. It is illustrated that leadership and its commitment for change is one of the single most important requirements for organizations. This comes with the role of NGOs and difference makers to create understanding and collaborative behaviour that developed over time in the long-term success (Waddock and Bodwell, 2007; Post et al., 2002).

In this paper, the author argues Gillberg and Miljöcentrum have demonstrated the path towards sustainability and engagement as change agent and leader. Even though, it started as an environmental activist with time and increased awareness of the stakeholders and economic development; Miljöcentrum strategies for change pressure and engagement have changed from activism to engagement, change agency and leadership as indicated based on the above three mini-cases.

Paper 5: Sebhatu, Samuel Petros, "The Challenges and Opportunities in Creating Sustainable Shared Values at the Base of the Pyramid - Cases from Sub-Saharan Africa", Kandachar Prabhu and Minna Halme (Eds.) Sustainability Challenges and Solutions at the Base-of-the-Pyramid: Business, Technology and the Poor, Green Leaf Publishing (September, 2008).

This paper is developed as a chapter of a book on the BOP. It is based on three case studies. The aim is to assess the prospects and difficulties of producers at the BOP to recommend how companies can contribute. The paper analyses the need for a more open and sustainable BOP approach to create sustainable solutions for the small-holders at the BOP that requires contributions from various actors: non-government agencies, entrepreneurs and multinational corporations. This can be achieved by exploring strategies for development using the trade approach and by creating sustained competitive markets.

The concepts are applied to a case study of a real business development initiative in Sub-Saharan Africa; i.e. the context of the Export Promotion of Organic Products from Africa (EPOPA), the Kenya Organic Agriculture Network (KOAN) and Ideal Providence Farms (IPF). The study reveals that such initiatives can be used as an active tool for advancing small-holder farmers and women by integrating them into a global value chain, leading to 
sustainable development, poverty alleviation, and value creation. This paper specifically focuses on integrating small-holders into a global value chain from a pro-poor (rural) perspective. It focuses on assessing the challenges and opportunities and makes an original contribution to the study of shared value by explicitly linking with the BOP thinking and sustainability.

\subsection{Structure of the Thesis}

Chapter 1 introduces the thesis and lays the ground for the subsequent chapters with the intention of establishing an overall aim and research questions. It examines some of the theoretical foundations, and describes and summarizes problems of the empirical aspects of the thesis. This is followed by a brief introduction of the appended papers, the authors' contributions to the papers, and the general research contributions of each paper.

Chapter 2 presents the research methodology and design (the research approach and method of source material collection). It explains the values and ethics of the research, and reflections on the actual research process and the methodological insights gained.

Chapter 3 describes the common theories and concepts of sustainable service business. It analyses the past and current static studies and contributions to corporate social responsibility, sustainable business, service-dominant logic, and service quality studies.

In Chapter 4, the contributions of the appended papers are discussed. The papers are reviewed with the research questions and overall aim in mind, in an attempt to summarize the contributions and unravel the dilemma of how CSR and S-D logic can contribute to the value creation process of sustainable service business.

Chapter 5 discusses the overall aim and answers the research questions presented in chapter one and the contributions of the appended papers. It discusses how it is believed that CSR based on business cases may contribute to the value creation process of sustainable service business. The reflections on my personal learning are included. The thesis takes as its starting point business cases and narratives and concludes with final reflections. 


\section{Research Methodology}

\subsection{Introduction}

This chapter contains a basic discussion of the research approaches used in the papers in this thesis. The methodological perspectives are primarily argued through qualitative research based on hermeneutics as the underlying philosophical approach. Case studies and narratives are used as specific research methods. This chapter will highlight the empirical studies of the appended papers, including the design, collection and analysis of the empirical resources. The research methods used for collecting source material are also discussed. The methods of empirical material collection are presented based on each of the appended papers in Section 2.3.

A distinction is made between the concepts of methodology and method (used in collecting the empirical material). The contribution of the appended papers is the next part of this section. I also reflect, in this section, on the trustworthiness and ethics of the research methodology. Finally, I present a model that illustrates how the theoretical and methodological parts are linked to the appended papers.

\subsection{The Research Approach}

The qualitative research methodology is a strategy applied for examining the available information and resource material in the thesis and appended papers. The methodology shifts from the underlying philosophical assumptions to research design, source material collection, interpretation and analysis.

In the table below (Table 1), the specific research methods employed in the appended papers are summarized. 


\begin{tabular}{|c|c|c|c|}
\hline $\begin{array}{c}\text { Research } \\
\text { Paper }\end{array}$ & $\begin{array}{c}\text { Type of } \\
\text { paper }\end{array}$ & $\begin{array}{c}\text { Research } \\
\text { approach }\end{array}$ & $\begin{array}{c}\text { Data collection } \\
\text { /method used }\end{array}$ \\
\hline Paper 1 & $\begin{array}{c}\text { Research } \\
\text { paper }\end{array}$ & $\begin{array}{c}\text { Qualitative } \\
\text { Case study }\end{array}$ & $\begin{array}{c}\text { In-depth case study of Paint } \\
\text { manufacturing plant }\end{array}$ \\
\hline Paper 2 & $\begin{array}{c}\text { Research } \\
\text { paper }\end{array}$ & $\begin{array}{c}\text { Qualitative } \\
\text { Case study - } \\
\text { Narratives }\end{array}$ & $\begin{array}{c}\text { Narratives - Five narratives } \\
\text { from IKEA, based on } \\
\text { interpretative approaches }\end{array}$ \\
\hline Paper 3 & $\begin{array}{c}\text { Research } \\
\text { paper }\end{array}$ & $\begin{array}{c}\text { Qualitative } \\
\text { Case study }\end{array}$ & $\begin{array}{c}\text { In-depth case study of four } \\
\text { MNCs. }\end{array}$ \\
\hline Paper 4 & $\begin{array}{c}\text { Research } \\
\text { paper }\end{array}$ & $\begin{array}{c}\text { Qualitative } \\
\text { Case study }\end{array}$ & $\begin{array}{c}\text { In-depth case study and } \\
\text { mini-cases of Miljöcentrum }\end{array}$ \\
\hline Paper 5 & Research & Qualitative \\
Case study & $\begin{array}{c}\text { In-depth case study of three } \\
\text { cases from sub-Saharan } \\
\text { Africa }\end{array}$ \\
\hline
\end{tabular}

Table 1: Summary of the appended papers

The common thread is that all qualitative modes of analysis are concerned primarily with textual analysis (whether verbal or written) (Taylor, 1976). The strength of qualitative research is its ability to provide complex textual descriptions, by gathering an in-depth understanding of the research issue. The qualitative method considers the description and understanding, and does not just answer questions of what, where, or when. However, it is essential to adopt an underlying philosophy to deal with the specific interpretational and analytical challenges of the qualitative research approach (Ghauri and Grønhaug, 2005).

Therefore, hermeneutics is applied in this thesis to deal with the challenges of interpretation and analysis. As a philosophical approach to human understanding, it provides the philosophical grounding for interpretation and reflection (Alvesson and Sköldberg, 2008) and it can be treated as both an underlying philosophy and a specific mode of analysis (Bleicher, 1980). As a mode of analysis, it suggests a way of understanding textual sources. Ricoeur (1981) develops one of the key philosophical reasons for this understanding of text. He uses the concepts of pre-text, text, and context to describe the discursive performances of the statements and signs (ibid.). According to Ricoeur (1974), interpretation is the work of thought that consists of 
deciphering the meaning hidden in the apparent meaning, in unfolding the levels of meaning implied in the literal meaning (ibid., p. xiv). Hermeneutics also includes practice in its theory of interpretation (Alvesson and Sköldberg, 2001; 2008). Most often in its history, hermeneutics has referred to the interpretation of texts. However, the term hermeneutics may also refer more sweepingly to the interpretation of meaning-whether in written texts, actions, or history. Historically, hermeneutics has been associated with the interpretation of biblical texts.

Hermeneutics is used to analyse texts in a way that looks beyond the surface features (e.g. of a parable) and to verify the analyses so produced. Hermeneutics encompasses not only issues involving written text, but also everything in the interpretative process. It traditionally involves interpretation of theories that concern the meaning of written texts. These theories focus on the relationships found among the author, reader and text. Hirsch (1976) argued that the meaning of a text is determined by the author's intent. The meaning of the text goes beyond the author, and is determined by the point where the horizons of the reader and the writer meet (Gadamer, 1994). This ensures that the text is independent of the author's intent and the original audience, and therefore the reader determines the meaning of the text (Ricoeur, 1976).

It is through the bermeneutic spiral, which refers to the dialectic between the understandings of the text as a whole and the interpretation of its parts, in which descriptions are guided by anticipated explanations (Gummesson, 2000). As Gadamer (1976) explains, it is a circular relationship. The anticipation of meaning in which the whole is envisaged becomes an explicit understanding in that the parts, which are determined by the whole, also determine this whole. This way of understanding and reflecting is extended by Alvesson and Sköldberg (2008). This philosophy of understanding, the cycle between pre-text and text for interpretation and analysis and the adoption as underlying philosophy has been applied in this research. 


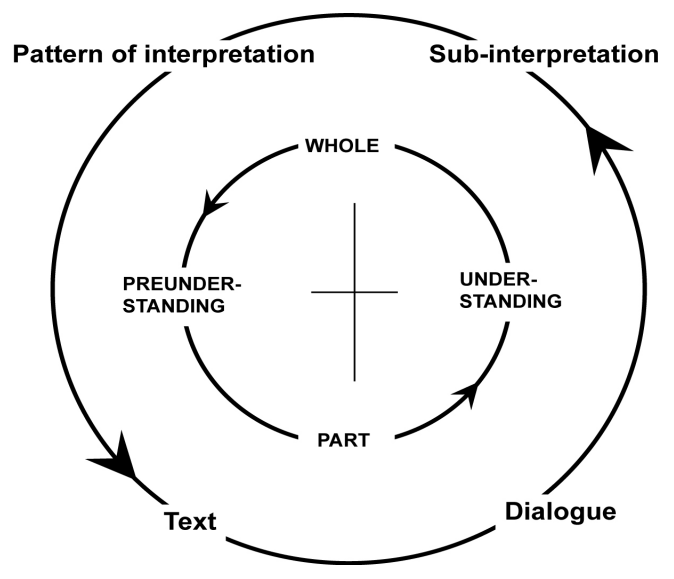

Figure 3: The hermeneutic circle basic version

(Source: Alvesson and Sköldberg, 2008, p. 66)

I have applied hermeneutics as a specific mode of understanding and analysis of the context based on the relevant collected source material (both primary and secondary) and the sphere of relationship between the object and that of subject. The primary research sources for my analysis were texts generated by interviews, literature reviews, observation, organizations' documents and reports, the Internet as a source of information and other relevant documents (published and unpublished). The appended papers apply different strategies to generate the empirical studies for my thesis. Even though the research backgrounds of these papers differ, they are very comparable in the way that the interviews were conducted. A person (interviewee) was asked to recall a meaningful understanding of a specific issue, such as through telling a story, an informal interview, discussion and observation. After a text was generated, one or more approaches were usually used to identify meaningful pieces of information, which in turn were used to generate themes or categories from a group of texts. These themes or categories communicate or interpret findings that reflect knowledge of the facts.

It follows from this point that I have an expectation of meaning from the context of what has gone before. The movement of understanding proceeds from pre-understanding to understanding and constantly from the whole to the part and back to the whole (ibid., p. 117; Alvesson and Sköldberg, 2008). In addition, this way of understanding and pre-understanding empowered my study by avoiding distance research, which has limited links to or contact with 
the actual subject of the research. It focuses on developing an understanding of a specific study (paper) (Gummesson, 2000).

The hermeneutic circle is also applied in my study to understand and assess the transformation of business from single bottom-line thinking towards sustainable business or organizational change (Alvesson and Sveningsson, 2008). The object of the interpretive effort becomes the overcoming the challenges of making sense of the organization as a text analogue (Alvesson and Sköldberg, 2008). The hermeneutic way of understanding and analysing becomes one of the methods to make sense of organizational issues, and the relationship among people, the organization, CSR and sustainable business.

\subsection{Research Methods}

\subsubsection{Case Study Approach}

Harrison and Freeman (1999), in their introductory essay, "Special Research Forum on Stakeholders, Social Responsibility, and Performance", in the Academy of Management Journal depict a distinction between case studies "designed with a purpose" with specific research questions and a deliberate case study design, and those that "just happened" while collecting data for another study. They believed that the former type of case study most likely contributes to new knowledge, which also allows deep study and analysis (ibid.; Eisenhardt 1989; and Yin, 1994). Yin (2003), defines the scope of a case study as: "A case study is an empirical inquiry that investigates a contemporary phenomenon within its real-life context, especially when the boundaries between phenomenon and context are not clearly evident" (ibid., p. 13). The construct of my thesis is also based on case studies, which are "designed with purpose" (Harrison and Freeman, 1999) to contribute to new knowledge (Gummesson, 2000; 2007b).

Case study research is used to gain insights in a wide sense. The term case study has multiple meanings. It can be used to describe a unit of analysis, for example a case study of a particular organization or to describe a research method. The discussion here concerns the use of the case study as a research method. Case study research is the most common qualitative method used throughout the papers. It allows conducting a thorough investigation and 
empirical enquiry of the organization and assessing the change process (Yin, 2003).

The critical type of case study is used in this thesis, as it is useful for answering cause and effect questions. It examines one or more areas to either examine a situation of unique interest with little to no attention to generalizability, or to challenge a highly generalized or universal assertion (Merriam, 1985). A critical case can also be defined as having strategic importance in relation to a general problem (Flyvbjerg, 2006). In this thesis, the critical case study method allows me to obtain deep insights into certain situations and phenomena characterized by complexity. This means an abundance of linked variables, unclear causality, ambiguity, ongoing change and unpredictability (Gummesson, 2008). A holistic view of an event or situation includes context as well as details, because phenomenon and context cannot always be distinguishable in real life. Moreover, richness of detail leads to a more complete understanding of some aspects of an organization, stakeholder, group, event or situation. The facts of the cases aid the holistic approach to context. Therefore, the design of the case studies in this thesis includes selection of cases, crafting instruments and protocols, and establishing a procedure for analysing the source material (Eisenhardt, 1989).

The case study method emphasizes depth rather than coverage and statistical generalization (Yin 2003; 1994; Gummesson, 2000; 2007b). However, this does not mean it allows triangulation. It is both a theory and a technique to describe reality and process resource material, not just verbally but also graphically and mathematically (Gummesson, 2008). Hoffmann (1999) defines abduction, deduction and induction as different steps of a case study process of inquiry. Induction is based on empirical evidence, while deduction is based on logic (Ghauri et al., 1995). Induction, in the appended papers, reflects the basic process of generalizations in the form of identifying local events that seem to have something in common. In an inductive approach, a rich and detailed description will be obtained from an extensive in-depth source material collection process (Gummesson, 2000; 2007b; 2008). From that understanding an assumption is derived that can be validated through deduction. Deduction is drawing conclusions through logical reasoning from a given assumption or premise, in the form of a research question or purpose of the study. Therefore, this process adds or subtracts understanding to the value of the general study (Ghauri et al., 1995). Abduction recognizes a particular or general pattern, and/or purpose. It is more about a deeper understanding of 
the phenomenon than merely testing it. These modes of a case study thus provide an opportunity for in-depth investigation and drawing conclusions. These also provided me with alternative ways to go beyond quantitative generalization. What is noteworthy about abduction and deduction in this thesis is that they both assume meaning: the meaning of each appended paper and the generalizations therein. Moreover, as the research approach demands, I tried to keep up to date with theories and ideas that were relevant for this scientific research method.

A frequent criticism of case study methodology is its incapability of providing a generalized conclusion. Yin (1994) cited Anthony Gidden's view, which considered case methodology "microscopic" because it lacks a sufficient number of cases. Gummesson (2000; 2008) presented an example of generalizations based on large observations. He argues that generalizations may be effective and efficient based on the use of in-depth studies, which is also proposed in this thesis. Hamel et al. (1993) and Yin (1994; 2003) and Normann (2000) forcefully argued that the relative size of the sample, whether it includes one or multiple cases, does not transform a multiple case into a macroscopic study. In this way, even a single case could be considered acceptable, provided it met the established objective, protocols, and establishing a procedure for analysing the source material. The in-depth study in my papers allowed me to perform a live experiment, test ideas, assess operational practices, and finally make generalizations and draw conclusions (Gummesson, 1994; 2000).

\subsubsection{Narrative Approach}

As I mentioned above, a tool to link my explanation and understanding in one of my papers is narrative method. This is to transform events and facts into organizational theory by demonstrating their ability to function as elements of completed case studies/stories (Boje, 2001; White, 1987). Barbara Czarniawska (1995) argues for a narrative approach in case studies as the notion of narrative knowledge comes close to the metaphor of the world-as-text (Czarniawska, 1997, p. 5). In her later book, she also introduced four forms of narratives in organizational studies. The third narrative form, which is organizational research that conceptualizes organizational life as story making and organizational theory as story reading (interpretative approaches) (Czarniawska, 1998, pp. 13-14), is applied in this thesis. With the narrative 
focus on "the story", its structure, linearity and coherence, my aim has been to tell the story of CSR in sustainable business and organization theory. As Boje (2002) argued, the story-telling in an organizational setting is non-linear, chaotic, multi-voiced and preliminary, and a narrative method has to take account of these characteristics. The plot and structure in some way combines the narratives into a meaningful whole (Czarniawska, 1999).

In an organization, managers and stakeholders can have confused, incomplete, unclear and contradictory views on many different issues. This suggests that the appended papers in this thesis should be perceived not as different papers but as a part of a unified and independent paper (Gummesson, 2000; Alvesson and Sköldberg, 2008; Johnson, 2008). Each appended paper is different and has specific content, which makes it exceptional and independent. However, the implicit meaning is part of the thesis with its own content, meaning and argument. Thus, the meaning of each paper can be understood as part of the thesis (Alvesson and Sköldberg, 2008).

\subsubsection{Source Material Collection}

Qualitative source material collection techniques for this thesis include interviews, observation (a plant tour), documents and texts. In general, in addition to the above-mentioned methodological concepts, this research project also applied the following three main methods in gathering the necessary source material for the appended papers. These methods are discussed below for each paper.

Interviews: In-depth, structured and semi-structured interviews were conducted. The in depth semi-structured interviews were conducted by letting the interviewees tell their stories based on the given context, which is flexible. This method allows new questions to be raised during the interview according to what an interviewee says. I had a well-considered framework of themes on the specific topics to be explored during the interviews. As a primary source of information, interviews with knowledgeable people, entrepreneurs and policymakers of the organization were conducted and the information gathered carefully analysed. Interviews were organized and conducted in both formal and informal ways: informally through telephone conversation, personal meetings and e-mail. Most of the interviews were formal, based on limited set of questions, although depending on the 
situation the interviewees were allowed to tell their stories. Before the interview, the necessary preparation was performed and additional questions were prepared in case they were regarded. The interviews on average lasted about two hours. Follow-up meetings and discussions were held as part of the informal interviews. All the interviews were conducted on-site or elsewhere outside the university. In total, seventeen formal interviews were conducted in addition to many meetings, consultations and discussions with people who knew or had an interest on these organizations, all of which is discussed under the source material collection process in the appended papers (Section 2.3.4).

Archival and library research: This study includes a colossal number of archival documents of different organizations, library material and Internet sources, including Internet articles, company and annual reports, press releases, NGO critical reports and news items. Organizations' internal documents, unpublished resources (rich material, mostly from consultants and companies) and NGO reports are the core resources. The material used in the appended papers is considered to be from primary sources. This resource material, for instance, was collected to assess the over more than 30 years history of Miljöcentrum and in the other cases over more than ten years of Flügger $\mathrm{AB}$. The other materials were annual reports of the companies and reports and publications of NGOs critical of these companies and other disobedient organizations, which are covered in the appended papers. Other materials were gathered from libraries, archives and the Internet within and outside the research site, including field-work, and are carefully analysed and interpreted.

Field research: This research was conducted as necessary in each case. For instance, field research was undertaken at the Flügger plant at Bollebygd and its surrounding area as a tour to analyse the general impact of an Environmental Management System (EMS) (ISO14001), at Flügger paint shops, at Miljöcentrum, at IKEA office, in various IKEA stores, in Ghana other organizations and at workshops. The tour to Flügger was to assess the implementation of EMS, meet the employees, conduct informal discussions and examine the bio bed and new store that had been built as well as to conduct an interview with the management. Personal observations, discussions and interviews were also conducted in Ghana in 
the case of Ideal Providence Farms. In addition, to obtain a profound understanding of organic farming and business, I attended closed training for more than a week. This was provided to more than 25 organic farmers, experts, representatives of NGOs and governments from Africa. Alongside researching and learning in this training, I also conducted interviews, informal discussions and developed future contacts.

\subsubsection{Source Material Collection Process of the Appended Papers}

This thesis has five appended papers. All the papers are based on empirical studies, based on cases studies and or mini-cases and narratives.

Study I: ISO 14001 as a driving force for Sustainable Development and Value Creation, The TQM Magazine, Vol. 19, No. 5 (August 2007).

This paper is a basic part of my master's thesis, advised by Bo Enquist, written in the spring of 2005. Enquist, as my advisor, saw the potential of this thesis and we decided to make it a research paper. I have studied the developments at Flügger AB (Sweden) over more than ten years (1994-2005) since 2004. The source material collection process in the case of Flügger $\mathrm{AB}$ began with a search for past studies. The search focused on past publications, especially Gillberg (1999) and media articles covering the controversy over HP-Färg and Kemi's reckless environmental actions. In the late 1980s and early 1990s, Flügger AB (Sweden) was severely criticized in the media for its irresponsible environmental actions, especially after a major incident involving a leak of organic solvents into the River Sörån that killed fish. Source material for the case study was also collected by analysing documents, raw source material and reports (internal and external), and collecting Internet documents and information.

To obtain a clear picture of the changes made, I undertook a tour of the paint plant and its surroundings, including the River Sörån. Based on an interview with a consultant from Milöcentrum and informal discussions with Flügger employees, I collected and analysed facts and made observations at the plant and prepared questions for an interview. In total, four interviews were conducted. One interview was with an environmental consultant and formal and informal discussions were also held at Miljöcentrum. Structured and semi- 
structured interviews with three Flügger $\mathrm{AB}$ employees in different managerial positions, including the Quality and Environmental Director and the Production and Laboratory Managers (Flügger Sweden and the Flügger Group) were conducted. I conducted all the interviews. Besides the interviews, I also met some employees informally. We used quantitative source material to analyse the progress made, such as market growth, environmental audits and revenue and production increases. This provided us with an extensive basis for developing this case. We also relied on experience and the literature to present the evidence in various ways using different interpretations and measurements, as the interest in this case relates to organizational change rather than specific problems.

Study II: Values-based Service Quality for Sustainable Business, Managing Service Quality, Vol. 17, No. 4 (July 2007).

The idea behind this paper, Values-based Service Quality for Sustainable Business, comes from Edvardsson et al. (2006), V alues-based Service Brands: Narratives from $I K E A$. To begin with, Enquist and I examined the internal magazine of IKEA entitled Read $M e$, with permission from IKEA, to decide what kinds of narratives to develop. The source material collection process began by assessing the empirical material collected from several master's theses supervised by Enquist (especially those on IKEA China) and other documents. These included a number of media articles, annual reports for more than five years, numerous documents and publications from different NGOs (as critiques of IKEA), Internet documents and information, and other relevant publications. In addition, I extensively perused secondary sources. I developed all the five narratives in this paper based on the information collected and the experiences of both Enquist and Edvardsson.

Two major interviews were conducted by Enquist and me with IKEA CEOs. The first was with IKEA Global Head of Social and Environmental Responsibility at Helsingborg-IKEA headquarters. The second was with the CEO of IKEA Japan (at that time) in Stockholm. Personal observations at IKEA stores in Sweden were made. As additional input, source material for the empirical part, for the five narratives, was also collected from multiple interviews made by Edvardsson and Enquist with IKEA managers over several years. Observations were made at different IKEA stores in Europe, 
Asia, and North America and informal interviews with both employees of IKEA and customers were conducted. This extensive research involvement provided us with a solid basis for selecting representative narratives for this article. All the five narratives chosen reflect the values-based thinking of IKEA.

I consulted Enquist and discussed the collected and analysed source material to narrate the stories several times before the paper was sent for publication.

Study III: Corporate Social Responsibility for Charity or for Service Business?, The Asian Journal on Quality, Vol. 9 No. 1 (2008)

The topic of this paper, Corporate Social Responsibility either for Charity or for Service Business is based on the empirical study of four multinational companies. The cases are IKEA, Starbucks, H\&M and The Body Shop. All the cases were developed by me in consultation with Enquist.

The development of the main case in this paper of the Swedish furniture producer, IKEA, is based on a study of several years. This has involved: (i) the extensive perusal of documents; (ii) two interviews by Enquist and me, and many others by Enquist and Edvardsson with IKEA CEOs and managers; (iii) the collection of narratives about IKEA from the media, the Internet, other documents (both internal and external) and books; (iv) personal observations at IKEA stores in different countries and cities and informal interviews with both employees of IKEA and customers; and (v) supervision of several master's theses on related subjects.

At the same time, I have also studied other cases of Starbucks, H\&M, and The Body Shop, mainly based on secondary sources and store visits with informal interviews with employees and customers. Our international master's program, which is tutored by Enquist, developed case studies and master's theses around these companies, and I selected source material in the same way as for IKEA. This extensive research involvement has provided us with a solid basis for selecting representative empirical source material for this paper. 
Furthermore, I conducted a secondary source material collection and analysis based on critiques of these companies. These include NGO publications, media articles, books and informal meetings with NGO members.

The sources collected were discussed and analysed several times with Enquist before developing them into cases and adding them to a matrix. The empirical study matrix was developed based on the theoretical framework and was compiled by me.

Study IV: The Role of Change Agents in creating Sustainable Business and Responsible Management-Case Study of Miljöcentrum, 12th QMOD and ICQSS conference, Verona, Italy (August 2009) (February 2010).

The choice of the case and the mini-cases was based on the strategies and initiatives of Miljöcentrum for environmental sustainability and applied sustainable business cases. It was also to identify their perspectives in accordance with the purpose of this paper to reflect on the contributions of this organization. I have followed and assessed the historical background and development of several years of a Swedish environmental NGO - Stiftelsen Miljöcentrum, to compile a case study of a change agent. The case investigates the work that Miljöcentrum has done for more than 35 years on pressure to change and the organizational change process. The case was selected after studying and assessing. The three mini-cases chosen may reflect the role of NGOs as change agents and different strategies reflecting the changing interests of the stakeholders at different times.

Source material for the case study and mini-cases was collected through both primary and secondary method. It was collected over a longer period between the years 2005 and 2009. I conducted six interviews and several formal and informal discussions with individuals who have known and followed Miljöcentrum for more than twenty years. Four of the interviews were with managers and department heads of organizations outside Miljöcentrum (for the mini-cases). One meeting and discussion was conducted with a CEO of another company, who worked closely with the founder and president of Miljöcentrum. To illustrate and assess the progress made thereafter, I also visited a plant and interviewed managers from the organizations that had consulted Miljöcentrum. Observations, attending shareholders meeting of 
VärmlandsMetanol, and analysis of documents and reports of Miljöcentrum (both internal and external- especially in the case of Flügger), collecting media articles, Internet documents and information, and relevant publications were also part of primary source material collection. I also examined Miljöcentrum publications including the Miljö o Framtid magazine (1972-1996), and other publications. I assed their documents and made both formal and informal discussions and meetings. One of the mini-cases (that of Flügger $A B$ ) was covered in detail first as a part of my master's thesis, then my other publication and later in my conference papers.

This has provided me with an extensive basis for developing this case. I also relied on experience and the literature to present the evidence in various ways using different interpretations and measurements, as the interest in this case relates to organizational change and leadership rather than to specific problems.

Study V: The Challenges and Opportunities in Creating Sustainable Shared Values at the Base of the Pyramid-Cases from Sub-Saharan Africa, Kandachar Prabhu and Minna Halme (Eds.) "Sustainability Challenges and Solutions at the Base-of-the-Pyramid: Business, Technology and the Poor", Green Leaf Publishing (September 2008).

Source material for the three cases in this paper was collected between 2006 and 2008. The choice of the three cases is based on the initiatives of different actors to alleviate poverty through trade in Africa. The cases were selected after meeting and spending more than one week with more than 25 organic experts, officials, farmers, entrepreneurs and representatives from all over Africa in Organic Agriculture Development (OAD) training in Sweden in July/August 2006. All the three cases chosen reflect the opportunities and challenges of implementing different initiatives at the BOP, especially in SubSaharan Africa.

For two years I have studied the development of the three cases: EPOPA, Ideal Providence Farms (IPF) and KOAN. In total, nine interviews were conducted between April and July 2006, with two CEOs and a staff member of Grolink and Torfolk Gard AB, the owner of Ideal Providence Farms, the leader and marketing consultant for KOAN, Kenya, the EPOPA Uganda 
project leader, beneficiaries of the project, consultants and experts. Moreover, two interviews were conducted in December 2006 and February 2007, with the management of Löfbergs Lila and Torfolk Gård AB. Personal visit to Ghana was also made in November, 2006. Follow-up discussions and updates were held, the latest in January 2008. Source material for these empirical case studies was collected through the analysis of documents and reports (internal and external) both qualitative and quantitative, media articles, Internet documents and information, and relevant publications.

This has provided me with an extensive basis for developing these cases. I also rely on my experience working with an SME in exporting marine products to Europe, the Middle East and the Far East, and on the literature to present and interpret the evidence in various ways based on the points of interest in these cases.

\subsection{Trustworthiness-Reflections of the Research Methodologies and}

\section{Design}

This research is based on some underlying notions of its validity and the appropriateness of the research methods applied. One of the most important requirements for a research paper is that it is regarded as reliable and the readers view it as consistent and trustworthy (Gummesson, 2000; Alvesson, and Sköldberg, 2008). A multitude of research methods was used to address these criteria (Ghauri and Grønhaug, 2005). Using qualitative methodology, I referred to different source material, used source analysis methods, and credible and updated theory as a method of reducing systematic bias, thereby increasing the validity of the findings of my studies by distinguishing the preunderstanding, understanding, and interpretation phases (Alvesson, and Sköldberg, 2008; Gummesson 2000). This was also to avoid the risk of becoming insensible to your own understanding (Sandberg and Targama, 1998). The endeavour of this research is to conduct an in-depth study of sustainable service business, service research and service quality over a longer period. Finally, based on the case study research on sustainability by Corcoran et al. (2004), I made an effort to include information on the theoretical approach to methodology and gathering material. 
In collecting and analysing source material, every aspect of ethical issues is taken into consideration. It was important for me to consider ethics in the process of collecting and analysing my research source material, especially interviews. I also maintain that observation needs special attention and authenticity. All of my papers employ field studies, observation and discussions with various individuals. Besides the interviews, I applied my past knowledge and experience in interpreting the source material. This required extra measures concerning ethics.

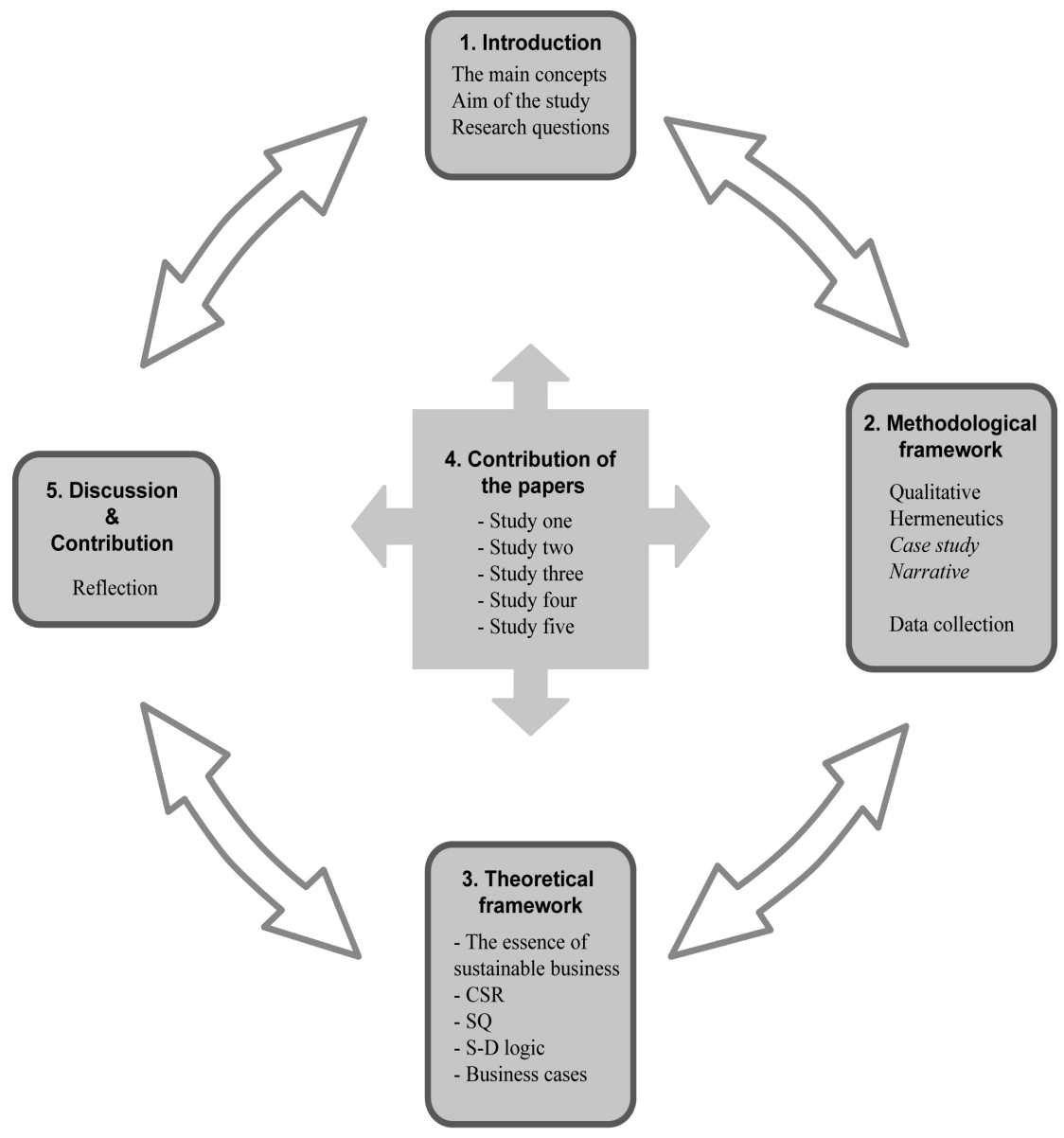

Figure 4: Model of the interrelationship of all the chapters in relation to chapter two 


\section{Theoretical and Conceptual Framework}

\subsection{Introduction}

\section{Business and the Necessity for Values}

Globalization has an impetus on sustainability and sustainable thinking of business. Globalization is a vigorous phenomenon that is rapidly transforming the political, social and economic environments of our planet in the $21^{\text {st }}$ century. This fast changing economic reality is strongly influenced by both the flatness of the world (Friedman, 2006; 2008) and the contribution of difference makers (Waddock, 2008) in the midst of increasing customer demands for value creation (Edvardsson and Enquist, 2009) and intensified global competition for markets. This change creates not only pressure but also the necessity for a new force of change for competitive advantage at both micro and macro levels based on social and ecological sustainability, which constantly force companies to be responsible and innovative and to develop both existing and new values (Normann, 2001; Edvardsson and Enquist, 2009; Laszlo 2008; Vogel 2005). The changing needs and demands for value creation also signify a new paradigm shift in management thinking (Vargo and Lusch, 2004; 2008; Lusch and Vargo, 2006). However, if organizations do not adapt to the change as an organizational culture and paradigm shift (Kuhn, 1996), the process risks failure (Alvesson and Sveningsson, 2008).

\subsection{Theoretical Background}

In assessing the history of sustainable development for sustainable business, which is a significant part of this study (Kuhn, 1996); it is imperative to integrate all bottom lines-ecological, societal, economic, ethical and philanthropic. However, the philosophy of this thesis is to describe my ongoing research interest in the area of sustainable development and business. Sustainable development provides the framework to integrate the environmental, social and economic dimensions of human activity at every level from local to global (Roome, 1998, p. 3). CSR is a sustainable development concept that emphasizes the importance of finding/keeping equilibrium among the basic interests of 
economic prosperity, social equity and environmental regeneration. The pressure for change and its process of involving entrepreneurs and leaders (managers) is transforming business thinking and strategies and prompting organizations to create social values (Edvardsson and Enquist, 2009). Vargo and Lusch (2004) also claim that S-D logic for value creation is emerging and a historical paradigm shift is developing.

In his noteworthy publication "The changing basis of economic responsibility" in the Journal of Political Economy, Maurice Clark wrote "twenty years ago an economist writing under this title would have been expected to deal chiefly or solely with the responsibility of the individual for his own economic destiny" (Clark, 1916, p. 209). This clearly indicates how familiar the world has become with the concept of social responsibility, which does not need to be continually rediscovered, but rather promoted among business organizations (ibid.). Concern of business for their immediate stakeholders or business responsibilities and value creation emerged in the 1800s in the USA and Europe with the expansion of modern industry and the proliferation of economists and organizational management thinkers. Although it is not a major focus of this thesis, the modern evolution of the concept of social responsibility of business in the $20^{\text {th }}$ century is briefly reviewed. Theodore Kreps in the 1930s introduced the subject of business and social performance and measurement. Peter Drucker in 1942 argued that companies have a social dimension. According to Mary O'Sullivan (2009), Drucker discussed this issue in depth in 1949. Howard Bowen in the 1950s held a general view of social responsibilities of business and theorized about the relationship between corporations and society with a definition of CSR (Bowen, 1953). Furthermore, in the 1960s and 1970s some other scholars addressed the issue of ethics and social responsibility of business and promoted CSR from different points of view (Narver, 1971; Bowen, 1953; Preston, 1975; Davis, 1975; Fitch, 1976; Carroll, 1979). This concern of businesses for society paved the way for organizations and management thinkers to seek different business models and ideas and to follow the greater shift to engage environmental issues for future generations.

The publication of "Silent Spring" (Carson, 1962), a book concerning environmental problems, was a milestone and motivated a new "ecological" vision of society. Although the environmental movement has a long history, concern has increased, especially after the establishment and expansion of various non-governmental organizations (NGOs) such as the WWF, 
Greenpeace, Oxfam and other consumer and environmental movements. These organizations have developed to become watchdogs and are critical of business. The new vision of environmental sustainability also became an increasingly prominent focus of international and national policy-making (Gummesson, 1994). The focus of the policy makers was to influence markets in the western world to ease everyday life and comprehend the market's effects on society, the economy and ecology. Environmental concerns also led to different national and international consumer movements and conferences in the 1970s and 1980s both in US and Europe, especially after the 1972 United Nations conference in Stockholm. The Stockholm conference paved the way for the emergence of sustainable development, although corporations were not present at this conference. This conference led to greater global attention to environmental sustainability, and opened the door for a variety of initiatives and research, such as the 1978 OECD re-launch of research into the links between environment and economy and its 1984 international conference. It also led to the Brundtland conference in 1987. Sustainable development as defined in Our Common Future in 1987 opened the door for broader discussions about and approaches to achieving a sustainable future. The publication of Our Common Future created wider awareness of sustainable development, which led to the establishment of the World Business Council for Sustainable Development (WBCSD) and the major United Nations conferences in Rio de Janeiro (1992) and Johannesburg (2002). Major corporations re-evaluated the seriousness of participation at the Rio de Janeiro conference, 20 years after the Stockholm conference (Gummesson, 1994). In the $21^{\text {st }}$ century, sustainable development is also becoming a part of globalization and the internationalization of markets and governance. Considerations of a sustainable future and environmental sustainability also marked a move by capitalism from the neo-liberal way towards the Millennium Development Goals (MDG) (Peet and Hartwick, 2009) and shared values of inclusive capitalism (Hart, 2007).

\subsubsection{Pressure to Change as it Relates to Corporate Responsibility}

Edvardsson and Enquist (2009) argue that creating sustainable value is a way for companies to advance their business priorities, achieve competitive advantage and drive innovation. Doing so in today's competitive context requires leading companies to consider carefully the social and environmental dimensions of their business activities (Laszlo, 2008). This can be achieved by 
integrating "societal" stakeholders such as NGOs and citizens as potential business partners rather than as illegitimate adversaries (Waddock, 2008). In recent years, NGOs have assumed an increasingly important role in society, and have come to influence corporate life (Teegen et al., 2004; Sjöström, 2008). In fact, they can be defined as coalescing around common ideas, needs or causes, and as collectively mobilizing their common interests. Several NGOs have raised awareness of issues related to corporate behaviour and social responsibility. Waddock (2008) indicates that the significance of these actors is that they establish new infrastructure for companies to be responsible, accountable and transparent, or in other words socially responsible. She further explains the process as:

- developing research and measurement tools,

- developing standards,

- fostering engagement and dialogue,

- questioning the system, and

- proposing alternatives.

However, some researchers argue that the role of business is only to maximize profit (Reich, 2008; Carr, 1996; Friedman 1970) and disagree with the role of business in society. The role of NGOs as corporate watchdogs has generally strengthened since the late 1970s and 1980s. The pressure to be socially responsible in business is also growing. Baron (1995), for instance, characterizes the social responsibility activities of business into two categories: (i) social responsibility used to respond to pressure groups or avoid threats and (ii) social responsibility in the absence of pressure groups. Baron (2001) in a paper written six years later explains that the social responsibility of companies is motivated by either altruism or profit maximization, even in the absence of external pressures. Therefore, actions to avoid a threat are usually profitmaximizing strategies as well (ibid.). Heal (2005) also indicates the advantages of social responsibility for companies; reducing conflicts with their stakeholders or activists may help companies build trust or reputation, which boosts stakeholders' confidence in them and protects their brands (Waddock, 2008). Furthermore, Sjöström (2008) argues that NGOs sometimes go as far as to enter capital markets to exercise shareholder rights or influence investors to campaign for certain issues. Several studies report that shareholder activism by NGOs is increasingly common, and the authors contend that NGO intervention on the stock market can be successful in changing business strategy (Waygood and Wehrmeyer, 2003; Guay et al., 2004; Sjöström, 2008). 


\subsection{Emergence of Social Responsibility}

Corporate social responsibility was first used and defined as a concept by Bowen (1953), who defined it as: "the obligations of businessmen to pursue those policies, to make those decisions, or to follow those lines of action which are desirable in terms of the objectives and values of our society" (p. 6). At the time, CSR was considered an obligation and was linked to the power that business holds in society. The thinking was that corporations, specifically, exist to provide products/services that generate profits for their shareholders. Carroll's $(1979 ; 1991)$ view is also of businesses' intent to improve important aspects of society or their relationships with communities. This role of social responsibility in business management has been a subject of debate for some time. Friedman (1970) in The New York Times Magazine, of 13 September, expressed a widely known and strong argument. He was asked whether a business could have any "responsibilities" other than to increase its profits. Despite strong objections by most researchers in this area, some still believe that the only role of business in society is sustainable profit maximization. They took Friedman's (1970) view a step further, arguing that a corporation's purpose is to maximize returns to its shareholders. Only individuals can have social responsibilities. Corporations (impersonal) are only responsible to their shareholders and not to society as a whole, and the one and only social responsibility of business is to maximize profits for its shareholders (Reich, 2008). The most extreme position on economic CSR was taken by Carr (1996) in his classic Harvard Business Review article "Is business bluffing ethical?", in which he indicates that the sole purpose of business is to turn out a product at a profit and argues for the impersonal nature of business. In spite of this thought, Grant (1991) dismisses Friedman's (1970) restricted point of view as fallacious, which is also supported by most researchers. This thesis also argues for the strategic view of CSR for the good of the society and its stakeholders based on triple bottom line thinking (Elkington, 1998; 2001; Vogel 2005), which is also the main focus of this section.

The CSR consideration of the good of society was inspired and promoted by various management theorists and neoclassical economists with the expansion of modern industry. The focus was intensified in the 1910s with the growth of corporate enterprises. According to the historian Chandler (1962; 1977), modern corporate enterprises were fully developed by the year 1917 . The progressive subsequent period, especially after the 1920s, developed a keener 


\begin{tabular}{|c|c|c|c|c|c|c|c|}
\hline 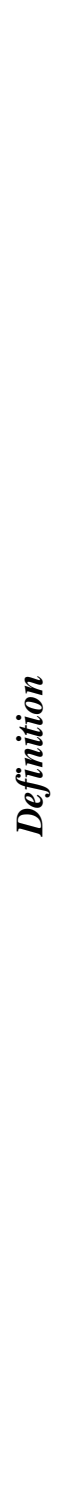 & 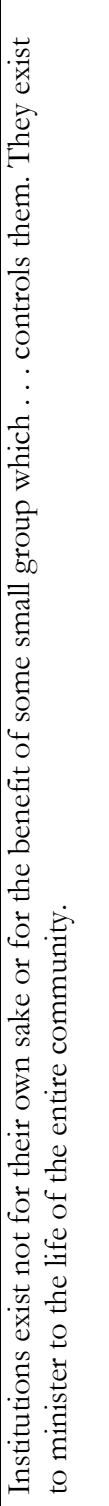 & 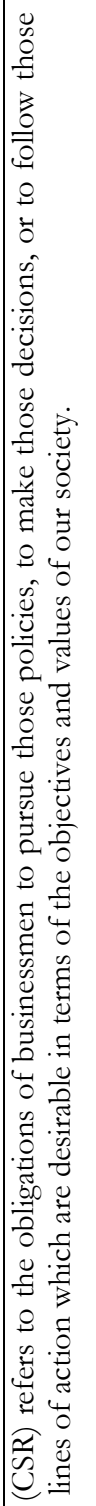 & 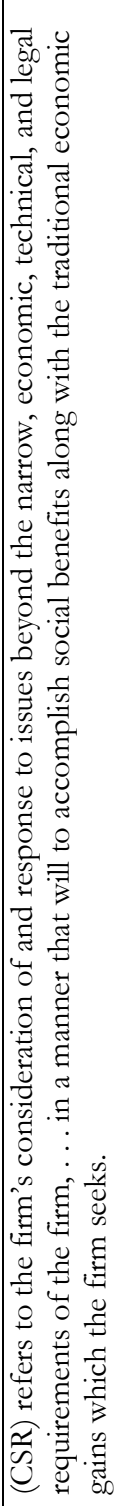 & 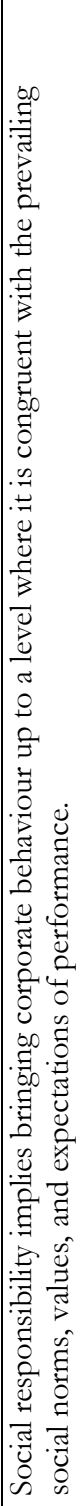 & 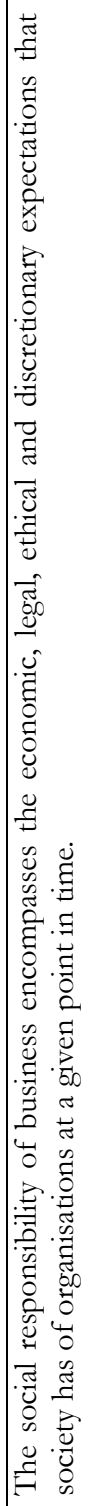 & 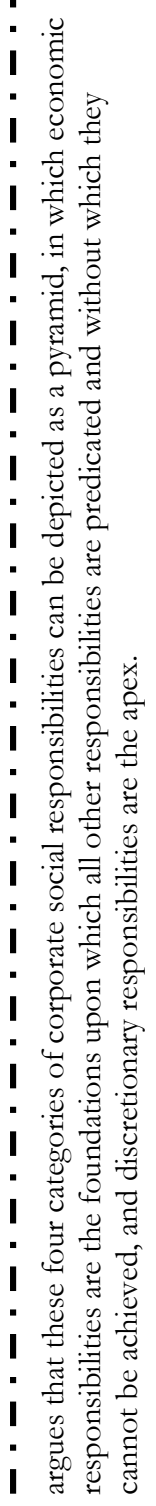 & 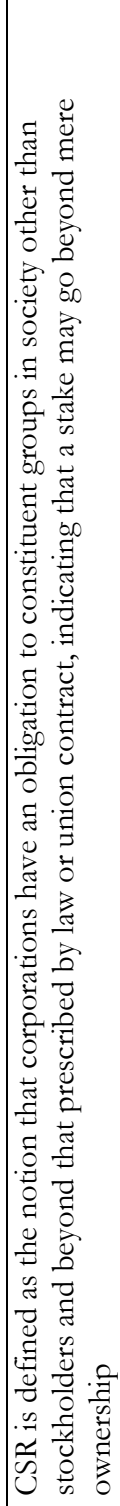 \\
\hline 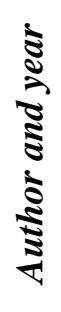 & 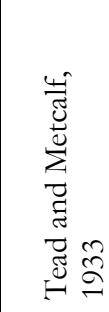 & $\begin{array}{l}\tilde{D} \\
\text { है } \\
\text { है } \\
\text { की }\end{array}$ & 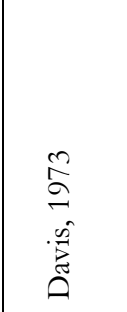 & 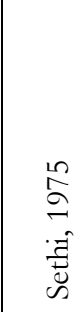 & 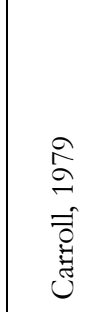 & 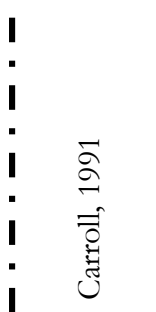 & $\begin{array}{l}\stackrel{0}{\mathscr{U}} \\
\stackrel{0}{0}\end{array}$ \\
\hline
\end{tabular}




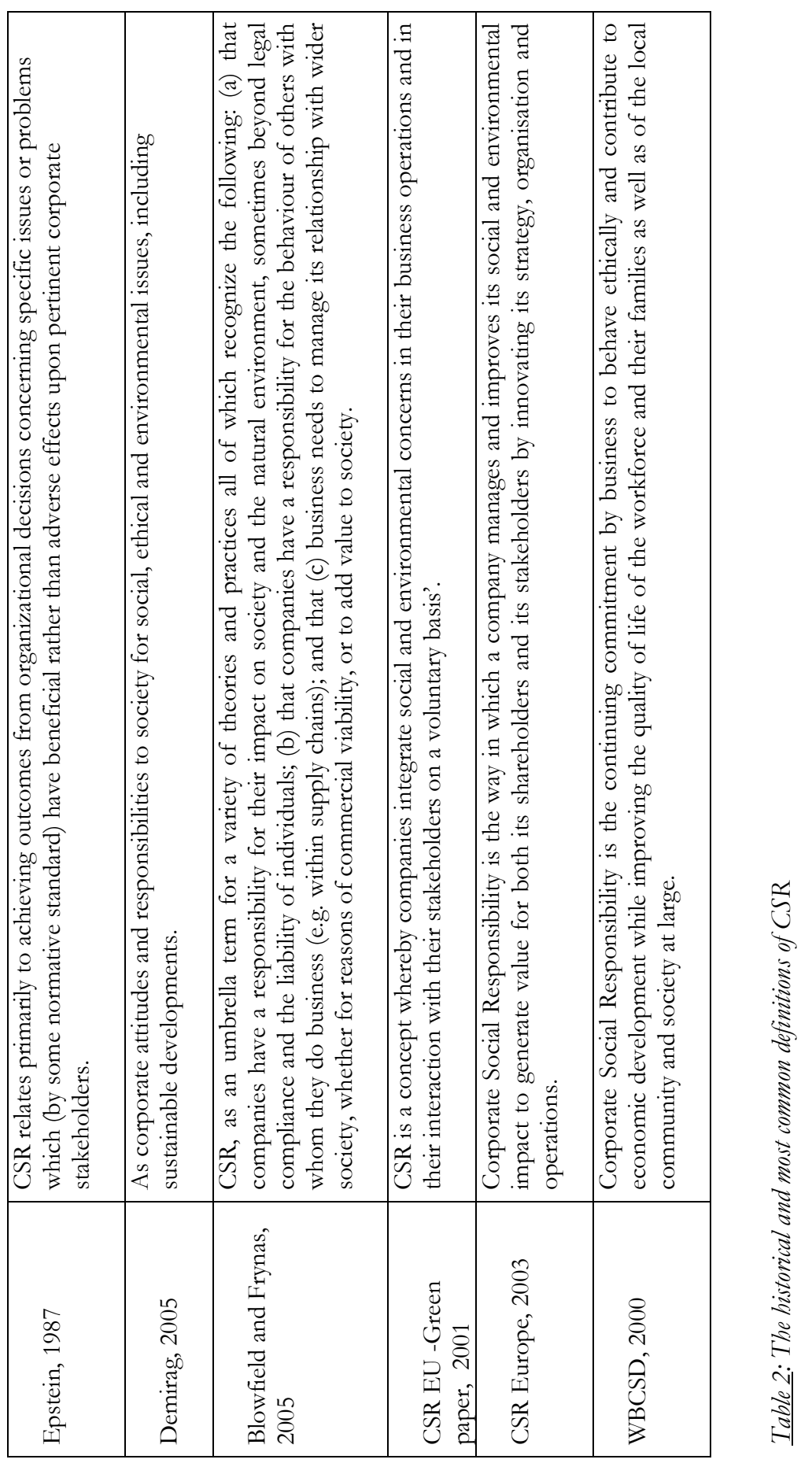


awareness of social demands as corporations lost their suspicion of government intervention (Hoffman, 2007). This suspicion accompanied social change such as urbanization and increased material wealth, particularly in the United States (ibid.). The CSR concern for the good of society became a focus of researchers in approximately the same period. Tead and Metcalf (1933), for instance, point out that business was not for the benefit of a minority, but for that of the entire community. Drucker in the 1940s analysed its effects on management. The early work of Goyder in 1960s on the so-called "responsible company" also referred to the various activities of the mid and late 1950s and suggested that social audits could provide a management tool and offer stakeholders a platform for challenging and influencing companies. This point was stressed by Davis, who (in 1960) described business social responsibilities as “the businessman's decisions and actions taken for reasons at least partially beyond the firm's direct economic or technical interest ... which need to be commensurate with the company's social power". Marens (2008) studies the history of CSR over half a century and Hoffman (2007) assesses the origins of modern corporate social responsibility. Hoffman (2007) tries to illustrate the dilemma by conducting a historical analysis of this concept. These historical studies raise the basic question of CSR's normative perspective on how to create value through strategic thinking. The factors enable the new industrial corporation to expand its role in society (ibid., 2007).

In general, the different studies and the debate over the responsibilities of business, their relationship with society and later towards the environment has been ongoing with broader arguments and discussion in the $21^{\text {st }}$ century. There is still no commonly accepted definition of CSR (Prieto-Carrón et al., 2006; Vogel, 2005; McWilliams and Siegel, 2001; Jones, 1995; 1999; Carroll, 1991; Hart 2007; Enquist et al., 2006; Edvardsson et al., 2006). Therefore, to examine the different definitions and usage of the term CSR and for the purpose of this thesis, I compiled the most commonly used and historical definitions of CSR in Table 2 below.

CSR definitions and concepts suggest that it is mainly defined as concepts and strategies by which companies voluntarily integrate social and environmental concerns with their business operations and stakeholder interaction (Enquist et al., 2006). In other words, CSR is the concept that an organization is accountable for creating economic benefits for its shareholders and is responsible for its impact on all relevant stakeholders, ecology and future generations. 
The concept of CSR is based on the triple bottom line (Elkington, 1998), i.e. economic, social and environmental, presupposes a balance between those three issues and creates a more holistic image of the complexity of sustainable development (Enquist et al., 2006; 2007). It is complex and multifaceted, covering a broad spectrum of topics from habitat conservation to energy consumption to stakeholder satisfaction and financial results. The adoption of environmental initiatives of a company for eco-efficiency (Schmidheiny, 1992) may be an essential bottom line that may also be the result of concern for social obligations and values (Hart, 2007; Bansal and Roth 2000; DeSimone and Popoff, 2000). Environmental efficiency is becoming a dynamic strategy, which presupposes that social expectations for corporate environmental performance are constantly increasing (DeSimone and Popoff, 2000; Hart 1997; 2007). To assess the concepts and their value to stakeholders, a broader view of how CSR can be implemented, integrated and measured is imperative. Therefore, different sub-topics are raised in this thesis, concerning how the sustainability of companies may be measured and how the process of change may progress in an organization. However, I also argue that the social bottom line is too narrow to integrate into companies' value networks, especially in the globalized world (Sebhatu, 2008). It is important to assess the value network to create a full picture of social responsibility and sustainability (ibid.). This thinking is starting to be discussed in most studies of CSR, because large companies are no longer MNCs but global (globally integrated enterprises (GIEs)) (Palmisano, 2006). Palmisano argues that business is changing in fundamental ways - structurally, operationally and culturally - in response to globalization and new technology (ibid., p. 127). This strategic thinking of companies is not only a response to pressure but also a new way of doing business. This wider thinking of inclusiveness is part of globalization and strategic thinking of companies and is referred to as base of the pyramid (BOP) thinking (Prahalad and Hart, 2002; Prahalad, 2005; Hart, 2007). The pressure on MNCs for wider social responsiveness (Kandachar and Halme, 2007) and inclusiveness are also part of the new capitalist thinking (Hart, 2007). Based on the above arguments and purpose of this thesis, I integrate the concept of BOP into the CSR concept below. 


\subsubsection{Base of the Pyramid (BoP)}

Epstein (2008) interprets the BoP concept as a differentiation strategy for companies to reduce social and environmental impact and improve their CSR performance. The BoP concept, as a new way of thinking and way of doing business (Hart and Christensen, 2002; Prahalad and Hammond, 2002; Prahalad and Hart, 2002; London and Hart, 2004; Ricart et al., 2004; Prahalad, 2005; Hart, 2007), may be a significant driving force for progress and for the creation of a new strategic approach. BoP refers to doing business with the poor at the base of the global socio-economic ladder who primarily do business in an informal market economy (London, 2007, p. 11). Most researchers in this field are debating how businesses deliver economic and social benefits to the BoP (Margolis and Walsh, 2003; Palmisano, 2006; Karnani, 2007a). Kandachar and Halme (2007) critically analysed this new approach and assess all the previous studies on BoP initiatives and strategies through different angles. They pointed out some of the many avenues of BoP for alleviating poverty including investing in education and engaging NGOs (ibid.). However, this thinking is still emerging and is the subject of debate. It raises the question: how can businesses engage all stakeholders and what is their contribution?

Prahalad (2005) suggests that the developing economy can be the engine of the next round of global trade and prosperity, and a source of innovation. Blowfield and Frynas, (2005, p. 503) claim that companies have a responsibility for the behaviour of others with whom they do business (e.g. within supply chains). Hart (2007) also argues for the importance of better infrastructure and communication links. In addition, Prahalad (2005) and Brugmann and Prahalad (2007) argue that multinational cooperation must occur for success in a BoP Market. However, Prieto-Carrón et al. (2006, p. 980) question how business can contribute to poverty reduction by stating two shortcomings. First, the terms "poverty" and "development" are frequently used but rarely defined, as in Prahalad's (2005) initiative and Kolk and Tulder's (2006) methodology. Second, previous studies of the relationships between business, economic growth and living standards have been largely overlooked. Businesses can create shared value at the BoP through positive social influence and by considering the poor as producers/employees, innovators and partners/entrepreneurs (Hart, 2007; Karnani, 2007a; 2007b; Sebhatu 2008; Simanis et al., 2005; Hart and Christensen, 2002; Ricart et al., 2004). 


\subsection{Service Quality Orientation for sustainable business}

Quality is one of the most important and strategic priorities for competitive advantage and an essential element for the development of companies. Quality management has been considered the most important aspect of the organization for enhanced business performance by managers, and researchers have underscored quality improvement initiatives that result in sustainable competitive advantage (Sureshchandar et al., 2002). However, quality is a more complicated and ambiguous term than it appears. Several researchers have assessed different approaches to defining quality. Garvin (1983) discusses five, including two (product based and manufacturing based) that refer to objective quality and one (user based) that parallels perceived quality. Schneider and White (2005) propose three approaches to defining quality: the philosophical approach, the technical approach and the user-based approach. In the userbased approach, the focus of this thesis, quality is determined by its user (ibid., p. 10).

To briefly assess the history of the existing quality thinking, although it is not a main interest of this thesis, the quality movement can be traced back to medieval Europe in the late 13th century, when craftsmen began organizing into unions called guilds. Until the early 19th century, manufacturing in the industrialized world tended to follow this craftsmanship model. In the early $20^{\text {th }}$ century, manufacturers began to include quality processes in quality practices. After World War II, quality specifically became a critical component of the war effort of the United States, where sampling techniques for inspection began to be used with the help of Shewhart's statistical process control techniques. The birth of total quality by Juran and Deming in the 1950s and 1960s also fostered new thinking in Japan. Total quality approaches began to embrace the entire organization. This has become known as total quality management (TQM). Later, new quality systems have evolved and quality has moved beyond manufacturing and into service, healthcare, education and government sectors. In the late 1970s, researchers from a variety of disciplines began to produce a now substantial body of theory and research devoted to understanding service quality (Schneider and White, 2004).

Service quality thinking to a great extent lies in the product quality and customer satisfaction literature (Brandy and Cronin, 2001). Grönroos (1984; 1994) and Parasuraman et al. (1988) define service quality in terms of customer 
satisfaction. It is a form of attitude, related but not equivalent to satisfaction, and results from a comparison of expectations with perceptions of performance (Parasuraman et al., 1988, p. 15). That is, the degree of fit between perceived quality and customers' satisfaction and expectations. To detect and understand non-verbalized customer needs, a sense of insight, a functional dialogue with the customer, and an understanding of his or her situation is required (Edvardsson, 1998). Service quality is linked to activities, interactions and solutions to customer problems (Edvardsson et al., 2006; Enquist et al., 2007). The definition is customer oriented, but it should not be interpreted as meaning that the service provider should always comply with customer needs and service attributes (Cronin and Taylor, 1992; Edvardsson, 2005).

Service quality delivery is becoming an essential strategy for winning and retaining customers, as indicated by various empirical studies (Ghobadian et al., 1994; Buzzell and Gale, 1987; Zeithaml, 2000). Edvardsson (2005) points out that service quality is perceived and determined by the customer on the basis of co-production, delivery and consumption experiences. He also concluded that it is linked to activities, interactions and solutions to customer problems (ibid.). Schneider and White (2004) indicate a relationship between service quality offering and profitability, which Heskett et al. (1997) express through the service profit chain model. Service delivery experiences that have emerged tend to focus on the process aspect of service offering. This can be measured through different types of measurements including service quality measurements. Commonly used techniques for measuring service quality experience are gap analysis (Zeithaml et al., 1988), SERVQUAL (Parasuraman et al., 1988), SERVPERF (Cronin and Taylor, 1994), critical incident technique (Bitner et al., 1990), Grönroos's model (1990) and Gummesson's typology (1992). This is a question about the nature of service quality, whether it is a perception of performance or disconfirmation (Suuroja, 2003).

Another question concerns the formation of service quality, whether it is a single construct or an aggregation of several dimensions/components (ibid., p. 8). Enquist et al. (2007) argue that SQ must be a construct with several components as Schneider and White (2004) indicate in their research perspectives on SQ. They discuss SQ as conceptualization and measurement from the perspectives of marketing, service operations customers and service climate, and also introduced SQ into human resource management. Lovelock (2000) also talks about the marketing imperative, the operations imperative and 
the human resources imperative. Furthermore, Schneider and White (2004) call for a broader perspective in SQ research and suggest the integration of TQM and other service offerings into operations management to create highperformance organizations by focusing on the bottom line (ibid., p. 156).

Assessing the contributions of service quality to sustainability is the other focus of this thesis. Gummesson (1994) proposes the term green service quality. Svensson (2006) also tries to describe sustainable quality management based on the implementation and evaluation of TQM. He assesses TQM's strategic approach by connecting it to corporate values. However, few empirical studies have been conducted based on this concept. Schneider and White (2004) proposition of the integration of TQM and other service offerings in the operations management provides another instance in which business trends are in alignment with sustainability, integrating different internal management systems for quality service delivery. It is also important to examine service logic (Vargo and Lusch, 2004a), which is about economic and social processes. This signifies the new thinking of incorporating different management systems in creating service quality. The new thinking of integrating service quality to create value is analysed in the next subsection.

\subsubsection{Shared values for Service Business}

Edvardsson and Enquist (2009) in their book make a great contribution on framing the values-based thinking of service business, based on the IKEA case. This study is a step toward to the service-dominant (S-D) logic thinking of Vargo and Lusch (2004) that gave rise to the question of what a service perspective on business can offer marketing in general. The view was widened immediately, based on surveys and observations of a number of leading international scholars in the field of service and service marketing. The key finding was that service was indeed generally considered to be more a perspective than merely an activity: "Service is a perspective on value creation rather than a category of market offerings" (Edvardsson et al., 2005, p. 118). During the 1990s and into the 2000s, the issue of value creation and the locus of value creation for customers became topics of interest in the management and the marketing literature. The prevailing view that value for customers is embedded in products that are outputs of firms' manufacturing processes, value-in-exchange, was challenged by the alternative view that value for 
customers emerges in the customers' sphere as value-in-use in value-generating processes (Normann and Ramirez, 1993; Holbrook, 1994; Ravald and Grönroos, 1996; Vandermerwe, 1996; Wikström, 1996; Woodruff and Gardial, 1996; Normann, 2001; Vargo and Lusch, 2004; Grönroos, 2006). According to this view, value is not created by the provider but rather by the customers' value-generating processes (Grönroos, 2000). As Vargo and Morgan (2005) point out, this is not a new approach to value creation but, in the economics and business economics literature, it has long been overshadowed by the valuein-exchange notion.

Furthermore, Laczniak (2006) illustrates the service-dominant logic for some societal and ethical dimensions. Enquist et al. (2008) extends Laczniak's (2006) view by using CSR for sustainable business service. Elkington (2001) argues that corporations could fuse values and value creation. In the dialectic between the economic, social, and environmental processes on the basis of the values base of the cooperation in respect to shared values and shared meanings, service culture drives service strategy (Edvardsson and Enquist, 2009; Edvardsson and Enquist, 2002; Edvardsson, et. al., 2006; Enquist et.al., 2007). The researchers mentioned above discuss the value of a strong service culture as a value-creating process, reproducing the logic of value as well as the logic of values (Edvardsson and Enquist, 2009; Edvardsson and Enquist, 2002; Edvardsson et al., 2006; Enquist et al., 2007). Pruzan (1998) puts forward a view of contemporary shifts in perspectives from control to values (ibid., p. 1379) and the adopted elements of "stakeholder theory" (Freeman, 1994; Elkington, 1998; Enquist et al., 2006; Laszlo, 2003) in talking about a contemporary shift in perspective from a focus on "control" to a focus on "values". According to Pruzan (1998), this requires a shift to "values-based management", which he premised on a stakeholder perspective of leadership, responsibility and ethics (ibid.). The values-based view places the company and its core strategy, structure and culture at the centre of a web of stakeholder relationships and shows how favourable relations can enhance organizational wealth (Post et al., 2002).

\subsection{Integrating CSR Business Cases}

The sustaining corporation must demonstrate its commitment and ability to work towards ecological renewal and develop key goals both inside and outside 
the firm founded on the pursuit of equity, human welfare and potential (Benn and Dunphy, 2004). Although recent CSR practitioners are mainly interested in the economic justification of establishing and communicating CSR, business cases suggest that financial gains could result from socially responsible activities by concentrating on the creation of markets-the "markets for virtue" (Vogel, 2005). This approach can be seen as a counter-argument to Friedmann's (1970) and other researchers' profit maximization view. Vogel (2005) utilizes a broader concept of CSR, describing it as "the market for virtue". He investigates whether there is a business case for CSR. Xueming and Bhattacharya (2006) also tried to answer the question of balance between CSR and profit making in their article based on secondary source materials where they investigate the relationship between CSR, customer satisfaction and market value. In contrast, other researchers present evidence that thriving CSR ensures competitive advantage and strategic gains (Kotler and Lee, 2005; Porter and Kramer, 2006). Margolis and Walsh (2003) conducted a large number of studies and found this affirmative relationship between social and financial performance.

The adoption of CSR as a defensive strategy based on business cases for the sake of appearances raises the question of the relationship between CSR and charity. Gummesson (2006) has been critical of mainstream marketing, whereby corporate sustainability becomes diluted into mere charity. Vogel (2005) has described this approach as "doing good to do good", which he has contrasted with a new understanding of CSR, whereby firms have the aim of "doing good to do well". In a similar vein, Kotler and Lee (2005) have argued for the simultaneous aims of "doing the most good for your company and your cause". Porter and Kramer (2002, p. 57) adopted a similar view when they contended that philanthropy per se might be in decline; however, when used in a proactive way, philanthropy can be a source of competitive advantage: "Most companies feel compelled to give to charity. Few have figured out how to do it well" (Enquist et al., 2008).

Enquist et al. (2006) conducted an important study of CSR as an institutional pressure on organizations. In analysing the effects of CSR, they cite Oliver's (1991) typology regarding strategic responses to institutional pressures as an important contribution to neoclassical economics. However, neoclassical economic theory provides no guidance on the ethical dimension of CSR. To fill this gap in institutional analysis, Enquist et al. (2006) discuss manifestations of CSR based on Oliver's (1991) typology. However, they argue that the 
explanatory power in a later case is weaker, especially in the context of a specific institutional pressure. They supplemented Oliver's (1991) typology with Roberts (2003) manifestations of CSR to understand the management practices of sustainable organizations.

Discussing business cases integrating sustainability thinking and assessing sustainable service organizations, Sebhatu and Enquist (2007) conducted an indepth qualitative study of the integration of environmental and quality standards based on business cases. They argued for the necessity of coalescing environmental sustainability systems and quality systems at the operational level to create sustainable organizations (ibid.). Enquist et al. (2008) integrated a model and matrix based on four well-known MNCs. They discuss in service research, Johnston and Clark (2001) proposed service operation in terms of a business focus, an operational focus and an encounter focus. CSR thinking was also adopted in their study and was analysed by Berry et al. (2006) in terms of nine "success drivers" (Enquist et al., 2008). The analysis resolves the argument over business cases of CSR. This study has proposed a descriptive framework for the analysis of CSR as an important element of a business model. Using this framework, the CSR business models of four companies (IKEA, Starbucks, H\&M and the Body Shop) have been described and analysed. The question now arises as to whether these CSR business models have been successful innovations in creating value. However, the nine drivers of Berry et al. (2006) can be used conveniently to assess CSR business cases with a view to establishing whether CSR drives successful innovative business (Enquist et al., 2008). This study is extended in the latest book by Edvardsson and Enquist (2009). Edvardsson and Enquist (2009) new book based on the IKEA case confirms its necessity for value creation and sustainable business. The main interest of the thesis is to adopt business cases to create a complete picture of value creation and sustainable business. 


\section{Contributions of the Appended Papers}

This chapter discusses the contributions of the five appended papers. I review the papers based on the aim and in view of each research question. This chapter contributes to the overall analysis and interpretation of the thesis.

\subsection{Contributions of Study 1}

Study 1 explores the approaches in standards and systems to sustainable service business and value creation beyond environmentalism (Welford and Jones, 1999). It describes the contribution of Environmental Management System (EMS)/ISO 14001 as value creators and the integration of service quality thinking in the process of organizational change. It is apparent that Flügger has been very successful from the perspective of sustainability and value creation, and that Flügger's commitment to the ISO 14001 process has been more than mere green washing (Vogel, 2005). The question that arises is whether this success was a result of the ISO 14001 process or whether it was a result of other factors. The study makes four contributions. First, it describes the implementation of ISO 14001, as was intended (Link and Naveh, 2006), and its affect on overall organizational change for sustainable business. Second, it connects the values of EMS and service quality. The integration of different internal management systems, namely ISO 14001 and ISO 9001, with a view to enhancing the delivery of quality service signifies new ways of thinking about sustainability, values-based value creation and service quality. Third, it develops performance measurement, quantitative and qualitative, based on triple bottom line and service quality thinking to assess the success story of the case. Fourth, sustainable value creation thinking, which requires more than adherence to external standards (Laszlo, 2003), requires a shift in mindset to make a revolutionary leap towards sustainable value.

An EMS is thus a systematic means of assisting organizations to manage the short- and long-term impacts of their products, services and processes on the environment. The paper argues that, if management is committed to a philosophy of SD and is prepared to be proactive in implementing appropriate programs in an era that promotes the environment as a value (Link and Naveh, 2006), an EMS should be helpful in transforming organizations and influencing 
stakeholder thinking to adopt a "triple bottom line" (Elkington, 1997) of economic, environmental and social sustainability.

The Flügger case, in this study, is a good example of the integration of different standards and systems, processes and concepts: ISO certification, TQM processes, service operations and service quality for sustainable service business. There has been a comprehensive shift of thinking in analysing and integrating environmental and quality management by incorporating it with sustainability. The environmental perspective extended the definition of customers to include stakeholders and defects, such as any form of waste (Corbett and Classen, 2006). The case reveals values-based thinking based on a customer-oriented approach with eco-friendly solutions in combination with the inculcation of a values-based corporate culture. Taken together, these initiatives produced a 300 per cent increase in market share. It is also argued that this is a success for what Edvardsson et al. (2006) have described as a "values-based brand". However, although many organizations have claimed competitive and market advantages as a result of implementing these standards and systems (Zutshi and Sohal, 2003), the Flügger case indicates that success requires external and internal perspectives to be complementary. A successful organizational change process requires values-based service thinking (Edvardsson et al., 2006) in which certifications and standards form part of a more comprehensive quality change process, including TQM and service quality based on the same organization's core values (Edvardsson et al., 2006).

\subsection{Contributions of Study 2}

Study 2 explores the relationship among the concepts of values-based service, service quality and sustainability. The study made an original contribution by presenting a new model of values-based service quality for sustainable service business (see Figure 5). The model is a result of a series of contributions of this paper. The model is derived from the analysis of the five narratives of IKEA (indicated in this paper) and the work of Edvardsson et al. (2006). It includes the five dimensions of sustainability identified by Kemp (2005): the "ethical", "social", "nature-philosophic", "economic" and "legal" dimensions. Four dimensions of values-based service quality were identified: "technical", "functional", "experiential" and "HRM and corporate climate". The scope of the study includes not only the "logic of value creation" but also the "logic of values" (Edvardsson and Enquist, 2002; Edvardsson et al., 2006). In a nutshell, 
the dimensions of values-based service quality and those of sustainability form the basis of the model of values-based service quality for sustainable service business that is the main contribution of this paper.

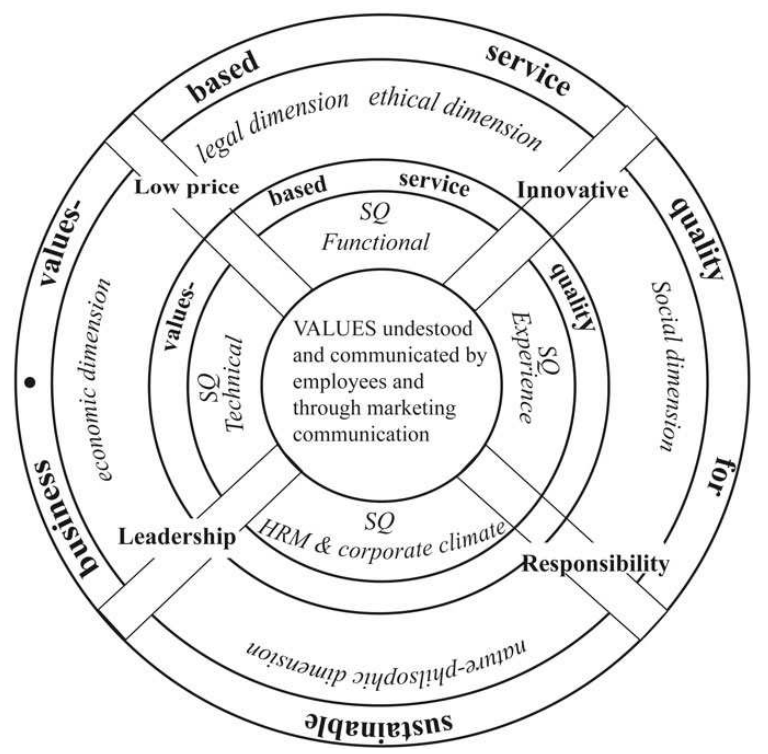

Figure 5: A model of values-based service quality for sustainable service business (Source: Enquist et al. 2007)

The study argues that values-based thinking not only includes the economic, ecological and social perspectives of Elkington's (1997) concept of a triple bottom line for sustainable development but also a stakeholder perspective of leadership, responsibility and ethics (Pruzan, 1998). Such values-based thinking can drive sustainable development according to Kemp's (2005) five dimensions of sustainability. These dimensions are believed to represent a deeper reflection on sustainable development and a more philosophical reflection on the practice of sustainable development.

According to Berry et al. (2006), many companies make incremental improvements to their service offerings but few succeed in creating service innovations that generate new markets or reshape existing ones. Vargo and Lusch (2004) conceptualized service quality from the perspective of economic and social processes, suggesting that service quality is a construct of several components. Schneider and White (2004) adopted a similar multifactorial view 
in perceiving service quality in a variety of ways. These included issues such as whether service quality is a single construct or an aggregation of several dimensions: marketing, service operations and HRM. This paper demonstrates that the logic of values as a driving force for value creation facilitates innovation of service quality to a greater extent than that previously achieved, if the focus is limited to the functional and technical aspects of service quality. In the analysis of the five narratives from IKEA, four dimensions of values-based service quality have been identified: "technical", "functional", "experiential" and "HRM and corporate climate". However, values-based service quality for sustainable service business, as argued in the paper, must be rooted in the values that form the provider's corporate culture. Moreover, these values must be communicated to employees and to the wider public through marketing and communication.

In general, the study contributes to this thesis by answering the research question. The concept of a values-based service quality presented here includes sustainability thinking as well as a stakeholder view. Corporate social responsibility and sustainable development can be used as driving forces for value creation as part of service-quality improvement (Enquist and Edvardsson, 2009) in sustainable service businesses. The business and normative cases of CSR should be embedded in the same values, and these should be communicated by employees who are "living the brand".

\subsection{Contributions of Study 3}

Study 3 combines corporate social responsibility and service logic. The study is central to the integration of all the appended papers. It makes an original contribution as the first article to integrate CSR thinking with service logic. The paper presents two conceptual and theoretical analyses: (i) CSR and its relation to profit and charity and (ii) CSR as part of a service business model. The study then illustrates these concepts with a matrix of comparative studies of four service firms, based on Johnston and Clark's (2001) description of a service operation perspective from a business focus, an operational focus and an encounter focus, and with particular emphasis on their different CSR activities and how these affect the mission of each company. All four service companies are global actors with strong values-based service brands (Edvardsson et al., 
2006) and have leading positions applying CSR as a driving force for business. They are IKEA, Starbucks, H\&M (Hennes \& Mauritz) and The Body Shop.

The study examines CSR as a business concept and its new content and meaning in a globalized world (Friedman, 2005). CSR associations refer to a company's commitment to social and environmental obligations, the idea of which is to create favourable "bonds" with customers and other stakeholders. This study further contributes to the understanding of a key management challenge: How can CSR be made a driving force for service business? This expands the service-dominant logic for some societal and ethical dimensions (Laczniak, 2006) with the help of CSR and illustrates through real business cases where CSR is an important part of value creation. In addition, this study focuses on the phenomena of CSR for value-in-use from a stakeholder perspective (Enquist et al., 2006) as a proactive part of service-dominant logic (Lusch and Vargo, 2006) and how CSR is used as a strategy for innovative service business. The study looks into Gummesson's (2006) broader view of marketing, and Laczniak's (2006) argument for an expansion of service-dominant logic to some societal and ethical dimensions. Laczniak (2006) expanded four of Vargo and Lusch's (2004) foundational premises (FPs): 3, 4, 6 and 8. This study counters the critique by Gummesson (2006) and also expands the service-dominant logic of some societal and ethical dimensions (Laczniak, 2006) by using CSR and showing real business cases where CSR is an important part of value creation and value-in-use from a stakeholder perspective (Enquist et al., 2006). To analyse and understand how CSR activities will govern these value creation processes for value-in-use (Vargo and Lusch, 2004) for stakeholders, a description based on a service operation perspective is required.

This also contributes to Vogel's (2005) and Xueming and Bhattacharya (2006) arguments that there is room for a business case for virtue in CSR for some firms and in specific circumstances (Vogel, 2005, p. 42). Xueming and Bhattacharya (2006), in their article, show that innovative companies practising CSR have a positive relationship with profit. In a brief literature review, the study outlines CSR activities as part of the service business model based on an expansion of the service-dominant logic (Laczniak, 2006).

The paper subsequently draws together the conceptual analysis and the case studies in a discussion of how CSR can be a proactive driver for innovative service business and confirms that there is a positive relationship between CSR 
and profit in innovative firms, as Xueming and Bhattacharya (2006) conclude from secondary source materials on the relationships between CSR, customer satisfaction and market value. The conclusion is based on the nine success drivers of market-creating service innovations identified by Berry et al. (2006) in successful market-creating service innovations. These drivers are: (i) a scalable business model, (ii) comprehensive customer experience management, (iii) investment in employee performance, (iv) continuing operational innovation, (v) brand differentiation, (vi) championing innovation, (vii) superior customer benefits, (viii) affordability and (ix) continuing strategic innovation. These nine drivers can be used conveniently to assess the CSR business cases examined in the present study to establish whether CSR drives successful innovative business.

This study of four well-known, global service-based businesses shows that CSR contributes to growth and profitability. CSR is part of the business model and can be used to create stakeholder value. The results suggest that there is not one formula for designing CSR in business models and strategy. Instead, companies must develop their own CSR strategies and culture to become successful.

\subsection{Contributions of Study 4}

Study 4 explores the role of NGOs as change agents in creating sustainable businesses and responsible entrepreneurs and leaders. The paper made an original contribution to the study of the role of change agents and pressure for change from external stakeholders on the organizational change process, based on the case of Miljöcentrum, which has been in the environmental sustainability movement for more than 35 years. The study presents a model (Figure 4) that integrates Total responsibility Management (TRM) (Waddock, 2008) with a strategic approach for quality improvement (Edvardsson and Enquist, 2006). The study, in general, makes three contributions. First, it assesses the NGOs role as change agents and in the empowerment of business to make a difference. Second, it considers the role of external pressure exerted on entrepreneurs and leaders, and third, it looks deeper into the strategies of NGOs' internal responses in creating sustainable business. This can be done through the contribution of difference makers and substantially changed thinking that clearly reflects companies' recognition of the mounting pressures for social responsibility and governance (Waddock, 2008). 


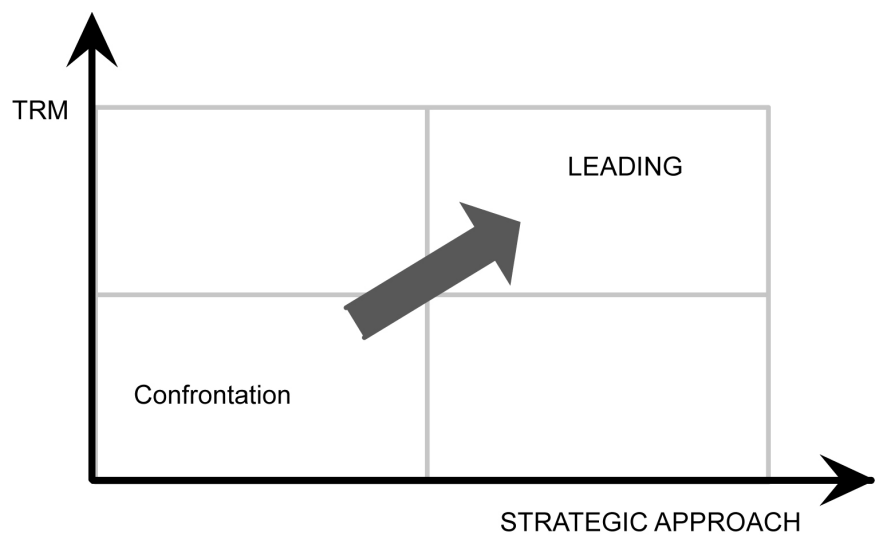

Figure 6: The proposed model for analysing change process

(Source: Sebhatu, Samuel, 2010)

Brown and Eisenhardt (1998) indicate that the changing needs of stakeholders, technological development and economic pressures contribute to the need for organizations to change significantly the way they think and act. The study examines this change, because it creates not only pressure but also a necessity for a new force for change for competitive advantage at both micro and macro levels based on social and ecological sustainability, which constantly forces companies to be responsible and innovative and to develop both existing and new values (Edvardsson and Enquist, 2009; Laszlo 2008). This substantial change clearly reflects companies' recognition of the mounting pressures for long-term profits, social responsibility and governance (Gummesson 2006; Waddock, 2008). However, this does not occur without the argument that NGOs can also weaken the business case by targeting companies that are starting to make efforts towards sustainability. It is still a substantial issue in business (Gummesson, 2008).

The study discusses the achievements of Miljöcentrum in creating pressure for reshaping strategies for competitive advantage and growth. However, these strategies can be adopted through systematic and processual strategic approaches (Whittington, 2001; Edvardsson and Enquist, 2006), which are practised by proactive companies. It is clear that the leadership's commitment to sustainable development and change is one of most important requirements 
for organizations; although, this comes with the obligation of NGOs and difference makers to create understanding and collaborative behaviour that develops over time to achieve long-term success (Waddock and Bodwell, 2007; Post et al., 2002). As part of this study, I applied the responsibility management concept of Waddock and Bodwell (2007), Waddock (2008) and Whittington (2001) to a model (Figure 4) to analyse and interpret Miljöcentrum's case.

Furthermore, although few studies have been conducted in this area of service research, Edvardsson and Enquist (2006) conducted a theoretical and empirical study of the pressure for change that derives from external pressure, a notion that is adopted in this paper by integrating it with the above-mentioned studies. The study demonstrates these concepts in a case study of a change agent-a Swedish environmental NGO, Stiftelsen Miljöcentrum-and in three mini cases. The case investigates the work performed by this organization for around 35 years and the mini cases concern pressure for change and organizational change process strategies.

\subsection{Contributions of Study 5}

Study 5 explores the challenges and opportunities for stimulating sustainable economic growth by and for the smallholders at the BoP (as producers and/or entrepreneurs). Based on multiple case studies from Sub-Saharan Africa, the study makes three contributions. First, it assesses the challenges and opportunities of sustainable BoP for the smallholders, in becoming commercially viable and creating "win-win" situations of shared value. Second, the engagement of stakeholders is part of the holistic CSR approach by companies, and especially affects those with whom they do business. Third, it proposes strategies of differentiation (Epstein, 2007) by MNCs that increase the market potential at the BOP and their brand image. This can be done through sustainability standards, which affect both the institutional structure and the form of governance of the global value chain.

According to London (2007), the BOP approach refers to doing business with the poor, at the base of the global socio-economic ladder. The concept, however, can be a significant driving force in the evolution of progress and in creating a new approach by forming strategies that increase the market potential of the BOP. The paper argues that it also demands a new way of doing business and the 
expansion of sustainable BOP strategies by MNCs to forge more open relations with smallholders in the developing economies, i.e. sub-Saharan Africa. Based on three cases, according to the notion of sustainable agriculture based on the sustainability thinking and standards of organic and/or fair trade labelling, farmers have the same opportunity for shared values as other stakeholders. The social and environmental certification and labelling programme creates an opportunity for smallholders to access the developed countries' markets by reducing some of the major barriers. However, this sustainable thinking requires contributions from different actors, e.g. NGOs, local stakeholders and entrepreneurs (Karnani, 2007; Kandachar and Halme 2007; Hart, 2007; Enquist and Sebhatu, 2006).

Ponte (2004) indicated that sustainability standards affect both institutional structure and the form of governance of the global value chain in creating better opportunities for smallholders and for MNCs and also in averting the challenges that they both face. Eco/social labelling is a way of creating shared value and "win-win situations". It strengthens the brands of MNCs. It also influences other stakeholders and customers in developed countries into making conscious decisions to buy eco/socially labelled products at higher prices. In general, the prospects created for smallholders, the success of projects for NGOs and networks, the business achievements of entrepreneurs and other actors and the opportunity for MNCs to act sustainably based on shared values show a win-win-win-situation, although there are some noticeable challenges. It is an opportunity embedded in sustainable values that stimulates economic growth without straining the ecosystem. Sustainable environmental and social standards encourage market competitiveness.

The cases of EPOPA, KOAN and IPF demonstrate that, in assessing the new approach of engaging with the poor, NGOs and local networks strategically contribute to engaging MNCs. They make a crucial contribution in easing and solving the existing pressure for market compliance and to the recognition of the poor as capable players in economic development strategies (Danse and Vellema, 2007). They also engage exporters and MNCs in value addition, certification and labelling as development partners. Their involvement transforms the smallholders into a part of the global value chain. For the MNCs, this is also a way of creating a holistic ethical approach and adopting a strategy that boosts their brand image. 
The cases have established the prospects of long-term positive consequences for sustainability thinking and the sustainable benefits for the smallholders, other stakeholders and the market. However, real success will not occur until the community of smallholders can be part of the globalized economy and real actors in creating value for themselves. Their achievements will depend on what happens to sub-Saharan Africa and its smallholders, entrepreneurs and partners. In fact, if MNCs establish genuine business relations with the BOP in accordance with their ethical values and sustainability standards, then the value to those smallholders would change the current situation regarding development. International trade has the potential to improve the lives of the world's poor far beyond the possibilities realistically offered by other means. The engagement of all stakeholders can also be operationalized as "sustainable BOP'. In other words, the BOP concept will be effective when it integrates the strategic components of differentiation strategy, standards and sustainable development. 


\section{Discussion and Contribution of the Thesis}

Inspired by the hermeneutic approach, in abductive way, I took the opportunity to analyse and interpret the appended papers in the light of the overall research questions and final reflection. This chapter integrates Chapters $1-4$ by analysing and interpreting the contribution of the thesis.

\subsection{Role of CSR in Sustainable Value Creation and Improvement of Service Quality}

What is the role of CSR in sustainable value creation and improvement of service quality? Studies 1, 2, 3 and 5 answer this research question. Enhanced awareness and utilization of value creation and co-creation in management thinking has created prevailing business practices and quality improvement. However, increasing consumer and stakeholder awareness of values has made CSR a driving force of service business and a key management challenge. A shift in mindset is required to make a revolutionary leap towards sustainable value. The emergence of CSR as a paradigm shift has a significant adverse impact on the market, which has thus forced businesses to embark upon a quality-improvement process. CSR illustrates through real business cases where it is an important part of value creation. Values-based thinking not only includes economic, ecological and social perspectives (the so-called "triple bottom line") but also a stakeholder perspective (of leadership, responsibility and ethics) and a value network (of seeking relationships). Such values-based thinking can drive sustainable service business.

The case of Flügger (paper 1) reveals values-based thinking based on a customer-oriented approach with eco-friendly solutions in combination with the inculcation of a values-based corporate culture. It is also argued that this is a success for a "values-based brand". A successful organizational change process requires values-based service thinking in which certifications and standards, in this case, form part of a more comprehensive quality change process, including TQM and service quality based on the same organization's core values. The effective cultivation of service quality for sustainable business involves the adoption and communication of attractive values, while simultaneously avoiding any association with negative values. However, adoption and 
communication of such values are in themselves no guarantee of success; implementation could also provide a collective "sense-making" without adequate discussion of why quality improvement is undertaken in the first place. If expectations are not based on a realistic assessment of needs and motives, they do not guarantee persistent improvements in sustainability. In this study (paper 2), a model was developed to assess the dimensions of valuesbased service quality. The dimensions of both values-based service quality and sustainability form the basis of the model of values-based service quality for sustainable service business.

The four case studies (paper 3) presented here have shown that companies that choose to act in a socially responsible manner do not necessarily use CSR in a defensive ploy in order to be seen as 'ethical'; rather, have utilised CSR as an essential aspect of their business models in a proactive strategy for: (i) doing innovative service business; and (ii) doing it well. It is apparent that CSR contributes to growth and profitability, and that CSR as part of a business model can be used to create value based service quality for all stakeholders.

The business cases demonstrate that ethics, accountability and service quality are key components of sustainability and sustainable competitive advantage, which are essential for creating and protecting stakeholder and shareholder value and developing a value network. These issues are explored by demonstrating how the adoption of a stakeholder perspective can also enable the BoP framework to be integrated into CSR for values-based thinking and thus become an important aspect of value creation. Sustainability standards as essential mechanisms may affect both the institutional structure and the form of governance of global business for enabling smallholders at the BoP to access markets and induce companies to act (as in the cases of paper five). This leads to strategic questions on not only how to link those communities at the BoP but also how to link required competencies or how to ensure that actors are performing functions tailored to their capacities in order to create efficiency. CSR values can act as a driving force for creating value in the supplier chain, wherein these values provide the direction of "shared values".

In general, the study contributes to this thesis by answering the research question. The concept of a values-based service quality presented here includes sustainability thinking as well as a stakeholder view. Corporate social responsibility and sustainable development can be used as driving forces for value creation as part of service-quality improvement in sustainable service 
businesses. The business and normative cases of CSR should be embedded in the same values, and these should also be communicated by employees who are "living the brand".

\subsection{CSR Values for S-D logic of Sustainable Service Business}

How do CSR values influence S-D logic for sustainable service business? This research question is related to almost all the studies conducted. Studies 1, 2, 3, 4, and (5) answer this research question. The concept of CSR refers to a company's commitment to its social and environmental obligations. By creating favourable "bonds" with customers and other stakeholders, CSR has been posited as a driving force for successful service business. It would thus appear that the role of CSR values in S-D logic is contingent on certain factors, including the nature of the specific business involved. S-D logic as part of CSR thinking can be applied to create stakeholder value (as in paper 3). S-D logic also conceptualizes service quality from the perspective of economic and social processes, which implies that service quality is a construct with several components (Paper 1 and 2). In general terms, CSR refers to a company's commitment to avoid being associated with unfavourable social/environmental phenomena, thus facilitating the creation of favourable bonds with customers and other internal stakeholders (such as employees and shareholders). Customers, NGOs and other stakeholders understand and endorse the values associated with a company. Such resonance of a company's values with those of its stakeholders can enhance value for the company and its stakeholders, but cognitive dissonance between them can destroy the potential value engendered by CSR (Edvardsson and Enquist, 2009).

This study counters the critique against S-D logic by expanding the societal and ethical dimensions by using CSR and showing real business cases where CSR is an important part of value creation and value-in-use. In addition, it focuses on the phenomena of how CSR is used as a strategy for innovative service business and how CSR can be a proactive driver for innovative service business and confirms that there is a positive relationship between CSR and profit in innovative firms. 
However, the adoption of CSR by a firm is not synonymous with customer awareness of CSR activities. The results of the studies suggest that there is no single formula for designing CSR in business frameworks and strategy. Instead, companies must develop their own CSR strategies and cultures by integrating value creation to become successful. This is assessed through business cases. To assess whether a service business includes CSR activities in the valuecreation processes, a perspective is required that is based on service operations in terms of a business focus, an operational focus and an encounter focus. Based on service operations, we developed a conceptual framework in paper three. The aim of this empirical study is to use the framework proposed above to offer a comparative analysis of the incorporation of CSR into proactive business cases.

Companies must have a "values-based service" that is incorporating economic, ecological and social values, and this involves a shift in the focus of managerial control from a preoccupation with financial issues to an awareness of the importance of a "triple bottom line" (TBL). This includes societal factors in addition to the traditional focus on economic measures.

In essence, if true sustainable business is the definitive goal, then a business initiative integrated into the core values that generates sustainable relations is a better solution than a CSR add-on intended to augment reputations or appease stakeholders. I argue that CSR values can drive value creation for value network even in the supply chain. The logic of values provides direction for "shared values". Business is changing in fundamental ways - structurally, operationally and culturally - in response to globalization and new technology. This shift from MNCs to globally integrated enterprises provides an opportunity to advance both business growth and societal progress. However, businesses must also make social compacts with NGOs, which are driven by strong values and have an inbuilt CSR framework.

The careful commissioning of a change agent by NGOs also creates rigorous solutions for the environmental and societal problems of the company, which are beyond purely environmental matters and affect both the economic and social bottom lines and the general culture of the organization. However, businesses should address the initial critiques from NGOs and other stakeholders, not by being defensive but by integrating their values with value creation and explicitly developing CSR strategies for distinctive local practices 
and structures. This can be achieved through entrenched ties and alliances with their stakeholders: customers, traditional partners (suppliers) and nontraditional partners (cooperatives, local communities, entrepreneurs, NGOs, aid agencies and others). Strategies embedded in social and environmental values may result in the achievement of common benefits for the company and all the stakeholders involved. The integration into diverse networks and NGOs, not only as watchdogs but also as partners, change agents and leaders, which leads to the development of long-term and cooperative relationships for value creation, as NGOs strategies and tactics of engagement changing.

\subsection{Final Reflection}

In this part, I reflect on my journey of research into sustainable values and value creation as inspired by hermeneutics. I reassess sustainable service business and the pressure of change agents using a metaphor from image to value.

\subsubsection{Sustainable Service Dominant Logic}

Value creation and co-creation in management thinking have created the prevailing business practices and quality improvement. During the past halfcentury, quality and social responsibility have influenced management thinking from different perspectives. Presently, S-D logic creates a platform for value creation and resource integration. Therefore, the roles of CSR, S-D logic and $\mathrm{SQ}$, as change pressures, are essential in creating an SB image. Service organizations may create their image for growth, profitability and efficiency based on their strategic decisions and management thinking. This depends on the integration of different change pressures for value creation, whether related to economic and social resource integration or values based. What kind of cocreation? Is it with value or values?

The emergence of CSR as a paradigm shift has had a significant adverse impact on the market, which has thus forced businesses to embark upon qualityimprovement processes. The integration of CSR and S-D logic also allows broadening of service quality improvement, but of course there is more to it than this. It signifies the new thinking: incorporating different management systems in creating the organizational change process, sustainability and finally a 
new values-based image of SSB. The process of transformation towards an SB image, to a values-based service business and SSDL is analysed using the framework shown in Figure 7.

One approach to service business is quality. Both managers and researchers have considered service quality management the most important aspect of the organization for enhancing business performance and creating value. This has underscored quality improvement initiatives that result in sustainable competitive advantage. Gummesson (1994) proposed the term green service quality, and some other researchers have described sustainable quality management based on the implementation and evaluation of TQM for responsible management. However, the wide array of SQ approaches still needs to integrate the values-based view of improvement and efficiency. S-D logic conceptualized service quality from the perspective of economic and social processes, which implies service quality must be a construct of several components. SQ does not have a stakeholder perspective, as it refers only to employees and customers, on which TQM, for example, also focuses. Recognition of a stakeholder perspective involves commitment to a wider perspective than SQ's traditional focus on customers and employees by involving all stakeholders. CSR through the lens of a company's strategies and operating practices, a practice based on a stakeholder view of the organization, is broadening the understanding of the stakeholders to whom a firm is accountable. This crafts the values-based service-quality thinking.

\section{FROM IMAGE TO VALUE}

\section{Change \\ Pressure}

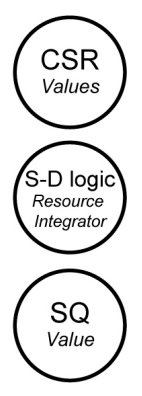

Service Business

Image

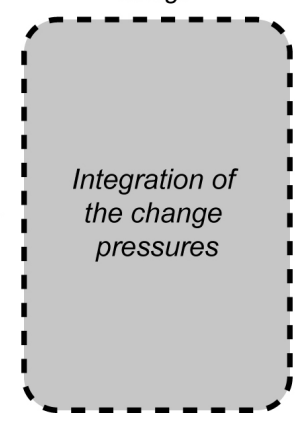

\section{Sustainable Service \\ Dominant Logic Value}

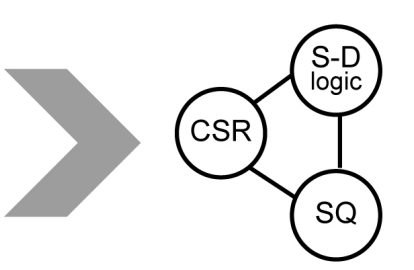

Figure 7: The SSDL business case model 
A successful organizational change process requires values-based service thinking in which SQ forms part of a more comprehensive quality change process, based on the same organization's core values. It is essential to have values-based thinking for value creation and engagement of the stakeholders. Values-based thinking drives value creation towards efficiency and improvement. This conception of service quality contends that there has been a contemporary shift in management perspective from a paradigm of 'control' to a paradigm of 'values'. The logic of values as a driving force for value creation facilitates innovation in service quality to a greater extent than that achieved if the focus is limited to the functional and technical aspects of service quality. This is assessed through business cases created within a sustainable business.

The author agrees with the notion that S-D logic is not inherently dyadic; it also shows the flexibility of both firm and customer networks and that S-D logic acts as a resource integrator. This allows companies to have a service business image based on value creation or co-creation. Value creation in S-D logic is determined by a sense of reciprocity and mutuality. It is reciprocal because a business exchange should be valued by both consumer and company with no obligation to behave in ways that reflect socio-cultural mores that are conducive to social well-being. Value is a central notion in S-D logic, as it is in many contemporary management frameworks and thinking, which allows service quality to inform efficiency and improvement. However, as discussed in this thesis, S-D logic emphasizes that human values determine economic value. The firm's/customer's value-creating network does not include broad ecological and societal concerns. It lacks a platform for strategic decisions and fails to integrate the missing values. The value that individuals put on objects of exchange, and hence the value derived from exchange, is determined by their values. Shifting from an individual to a societal perspective, we differentiate between personal values and societal values. Even though S-D logic proposed a great paradigm shift, it still does not explicitly discuss the transformation of values into value, just as some management discussions still do not allow the consideration of values in value.

This thesis takes a broader view of service marketing critiques and argues for an expansion of service dominant logic to some societal and ethical dimensions and the integration of CSR. The author argues the need for enhanced awareness and utilization of CSR to become a marketing practice in service businesses, to allow values to drive value. It is time for the CSR framework and values-based 
thinking to permeate S-D logic. The thesis also counters the critiques of some researchers of the expansion of S-D logic using CSR by showing real business cases where CSR is an important part of value creation and value-in-use from a stakeholder perspective, as indicated in Figure 8.

CSR activities will govern these value-creation processes for value-in-use. However, strong corporate values both bring value-in-use to stakeholders and affect the image. From the literature review on this subject, it is apparent that there must be a 'good fit' between the internal and external perspectives of a service company. To achieve this, the core values of the firm appear to play a crucial role in sustaining the image. Values-based service shifts the focus of managerial control from a preoccupation with financial issues to a wider awareness of CSR and the importance of triple bottom line thinking. This kind of thinking forces organizations to rethink their standard business model, increasing interest in innovative services (value creation and co-creation), based on the challenge of global sustainable development. Innovative companies practising CSR have a positive relationship with profit. This also contributes to the argument that there is room for a business case for virtue (Vogel, 2005, p. 42) in CSR for some firms and in specific circumstances.

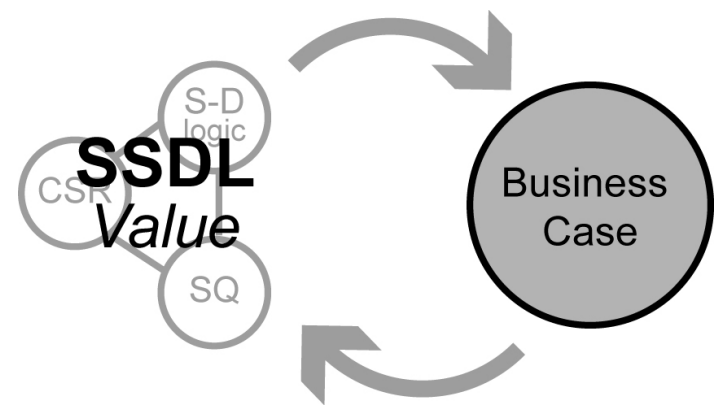

Figure 8: Understanding SSDL through business cases

Companies using an evolutionary strategic approach that envisages more than just profit making can adopt this approach. Proactive multinational companies, such as IKEA, The Body Shop, Starbucks and H\&M, as analysed in this thesis, practise this strategic approach. The same practice can also be seen in small and medium companies, based on standards and initiatives, as in the case of Flügger AB. A shift in mindset is required to make a revolutionary leap towards 
sustainable value, which we have analysed through business cases for sustainable business. These business cases also demonstrate that ethics, accountability and service quality are key components of sustainability and sustainable competitive advantage, which are essential for creating and protecting stakeholder and shareholder value and developing a value network. Insights from sustainable business practice provide opportunities to reshape strategies for competitive advantage, quality and values-based thinking. Value creation for customers (S-D logic) based on businesses' social and environmental values is in accord with the shared values of customers and other stakeholders. Therefore, the conceptual framework of a paradigm shift can be generalized to new thinking in Service Dominant Logic (S-D logic) and the social responsibility of businesses as the major phenomenon of the changing and globalizing business environment. In this thesis, we have used 'Sustainable Service Dominant Logic' (SSDL) to argue that value-based co-creation of the S$D$ logic framework can be used to create values-based services for sustainable business by examining the link between CSR and S-D logic based on value, values and service quality for sustainable business. This is this thesis's contribution to the ongoing discussion of the paradigm shift in service research.

CSR, S-D logic and SQ have made the same journey but followed different avenues. CSR, quality and service research were fundamental concepts for the paradigm shift of the second half of the 20th century.

\subsubsection{Sustainable Service Business - The Future}

The metaphor of sustainable service business may be analysed based on the proactive thinking of managers, entrepreneurs and business leaders in creating social values and responsible organizations. This can also be seen as the integration of organizational thinking and the emergence of sustainable thinking in business. This expression travelled with the author for at least the past four years, after reading Carson (1962) and listening to environmentalist's reflections. However, Friedman's 'Where Birds Don't Fly' statement (2008) created a discrepancy. The author use the word 'discrepancy' not in the way Friedman used it for his reflections on the post of September eleven (9/11) world, but rather as discrepancy between what was and what will be in creating value and the values of business. 
This creates the fundamental question of image and business model, which leads to the evolution of new sustainable business thinking: if we recognize that we are nature, how do we organize our businesses? (Tällberg Forum meeting, 2008). This question forces organizations to rethink how to escape from their nest of the standard business model towards satisfying their increasing interest in product and service innovation based on the challenge of global sustainable development and to develop new ways of engaging. The emergence of green thinking with green marketing is one of the lead-the-way developments that provide the input, which deals with the transformation process of integration into a values-based image and business model.

The focus on the process of growth of companies is always on major change in creating image (brand) based on the entrepreneurs' philosophy and increasing shareholders value by maximizing profits. In the globalized world and in the transformation towards values-based thinking, a major change of image and structure is imperative for companies' survival and future. This means that service businesses practise ethical behaviour and responsible management, respond positively and with agility to stakeholder demands and, when under pressure to change, conspicuously and relatively abruptly change their image and structure. This approach also requires a business to integrate different approaches to change to create an SSB image depending on its business model. The integration of CSR thinking into service business creates a values-based image. However, there is a risk that current pressures to seem 'green' push companies towards doing the wrong things better, rather than learning to do the right things. It is also a common phenomenon that organizations add a suffix to their names proclaiming themselves to be 'sustainable', 'socially responsible', 'environmentally caring', 'ethically managed', and so on, to create a 'green image'. This could be a negative response to change pressures, or a misunderstanding - a reaction from the organization's public relations services and communications strategy that amounts to no more than 'green washing'. This we cannot afford. Instead, we must dare to think about business in new ways. The pressure from external stakeholders, mainly non-governmental organizations (NGOs), as drivers of change may also contribute strongly to this endeavour. This substantial change pressure clearly reflects companies' recognition of the mounting pressures for social responsibility and governance. The relationship between business and NGOs, especially green advocates, can be strained at the beginning of this change process; however, it can also be turned into collaboration as a way for responsible companies to enhance their 
mutual sustainability objectives, creating values that derive from the external pressure and harmonize CSR as part of the company strategy. The inevitability of the role of change agents for sustainable development is to transform the mindsets of entrepreneurs, leaders and managers regarding their organization's values, communicating and implementing strategies through proactive thinking.

FINALLY, the journey of research into sustainable business and SSDL is just beginning. I urge other researchers to join the journey and deepen the study of this important phenomenon. 


\section{REFERENCES}

Abela, A. V. and P. E. Murphy (2008), "Marketing with integrity: ethics and the service dominant logic for marketing," Journal of the Academy of Marketing Science, 36 (1), 39-53.

Alvesson, M. (2002), Understanding Organizational Culture. London, SAGE.

Alvesson, M. and Karreman, D. (2007), Constructing mystery: Empirical matters in theory development, Academy of Management Review, Vol. 32 No. 4, pp. $1265-1281$.

Alvesson, M. and Sköldberg, K. (2008), Reflexive methodology: new vistas for qualitative research. $2^{\text {nd }}$ edn., SAGE, London.

Alvesson, M. and Sköldberg, K. (2000), Reflexive methodology: new vistas for qualitative research. SAGE, London.

Alvesson, M. and Sveningsson, S. (2008), Changing organizational culture: cultural change work in progress. Routledge, London.

Bansal, P. and Roth, K. (2000), Why companies go green: A model of ecological responsiveness, Academy of Management Journal, Vol. 43, No. 4, pp. 717-736.

Baron, D.P. (1995), Business and its Environment. Prentice Hall, NJ.

Baron, D.P. (2001), Private politics, corporate social responsibility, and integrated strategy, Journal of Economics \& Management Strategy, Vol. 10, No. 1, pp. 7-45.

Bergström, S. and Gummesson, E. (1995), Green service quality and it's indicators: lessons from a restaurant application, in Olsen, M.D., Teare, R. and Gummesson, E. (Eds.), Service quality in hospitality organizations, Cassell, London.

Berry, L.L., Shankar, V., Parish, J.T., Cadwallader, S. and Dotzel, T. (2006), Creating new markets through service innovation, MIT Sloan Management Review, Vol. 47, No. 2, pp. 56-63.

Bitner, M.J., Booms, B.H. and Tetreault, M.S. (1990), The service encounter: Diagnosing favorable and unfavorable incidents, Journal of Marketing, Vol. 54, No. 1, pp. 71-84. 
Bleicher, J. (1980), Contemporary hermeneutics: hermeneutics as method, philosophy and critique. Routledge, London.

Blowfield, M. and Frynas, J.G. (2005), Setting new agendas: Critical perspectives on corporate social responsibility in the developing world, International Affairs, Vol. 81, No. 3, pp. 499-513.

Blowfield, M. (2005), Corporate social responsibility: Reinventing the meaning of development?, International Affairs, Vol. 81, No. 3, pp. 515-524.

Bowen, H. (1953), Social responsibilities of the businessman. Harper, New York, NY.

Brown, S.L. and Eisenhardt, K.M. (1998), Competing on the edge: Strategy as strategy chaos. Harvard Business School Publication, Boston, MA.

Brugmann J. and Prahalad C.K. (2007), Co-creating business's new social compact, Harvard Business Review, Vol. 85, No. 2, pp.80-90.

Buchanan, D., Ketley, D., Gollop, R., Louise, Jones J., Saint, Lamont S., Sharpe, A. and Whitby E. (2003), No going back: a review of the literature on sustaining strategic change, Research Into Practice Team, NHS Modernisation Agency, St John's House Leicester; available at http://www.modern.nhs.uk/researchintopractice (March 2005)

Buzzell, R.D. and Gale, B.T. (1987), The PIMS principles: Linking strategy to performance. Free Press, New York, NY.

Carr, A.Z. (1968), Is business bluffing ethical?, Harvard Business Review, Vol. 46, No.1, pp.143-153.

Carroll, A.B. (1979), A three-dimensional conceptual model of corporate performance, Academy of Management Review, Vol. 4, No. 4, pp.497-505.

(1991), The pyramid of corporate social responsibility: Toward the moral management of organizational stakeholders, Business horizons, Vol. 34 No. 4, pp. 39-48.

(1999), Corporate social responsibility: Evolution of a Definitional Construct, Business \& Society, Vol. 38 No. 3, pp. 268-295.

Carson, R. (1962), Silent spring. 10th edn., Houghton Mifflin, Boston, Mass.

Carter, C.R. (2004), Purchasing and social responsibility: A replication and extension, Journal of Supply Chain Management, Vol. 40 No. 4, pp. 4-16. 
Cheney, H., Nheu, N. and Vecellio, L. (2004), Sustainability as social change: values and power in sustainability discourse; In Cheney Helen, Katz Evie, Solomon Fiona (eds.), Sustainability and social science: Round table proceedings, The Institute for Sustainable Futures, Sydney and CSIRO Minerals, Melbourne, July, pp. 225-246; available at http://www.minerals.csiro.au/sd/pubs/ (March 2005)

Clark, J.M. (1916), The changing basis of economic responsibility, The Journal of Political Economy, Vol. 24 No. 3, pp. 209-229.

Corcoran, P.B., Walker, K. and Wals, A.E.J. (2004), Case studies, make-yourcase studies, and case stories: A critique of case study methodology in sustainability in higher education, Environmental Education Research, Vol. 10, No. 1, pp. 7-21.

Cramer, J. (2006), Corporate Social Responsibility and Globalisation: an action plan for business, Green-Leaf Publishing, Sheffield.

Cronin, J.J. and Taylor, S.A. (1994), SERVPERF versus SERVQUAL: reconciling performance-based and perceptions-minus-expectations measurement of service quality, Journal of Marketing, Vol. 58, No. 1, pp. 12531

Czarniawska, B., (1995) Narration or Science? Collapsing the Division in Organisation Studies, Organisation, Vol. 2, No, 1. pp, 11-33

Czarniawska, B. (1998), A narrative approach to organisation studies. SAGE, London.

Davis, K. (1973), The case for and against business assumption of social responsibilities, Academy of Management, Vol. 16, pp. 312-22.

Davis, K. (1975), Five propositions for social responsibility, Business Horizons, Vol. 18, No.3, pp.19-24

Demirag, I., Barry, J. and Khadaroo, I., (2005), Concluding remarks on emerging governance structures and practices: the state, the market and the voice of civil society; in Demirag I. (Ed.), Corporate Social Responsibility, Accountability and Governance: Global Perspectives, Greenleaf Publishing, Sheffield, pp.351-360.

DeSimone, L. D. and Popoff, F. (2000), Eco-Efficiency: The business link to sustainable development. The MIT Press, Cambridge, MA.

Drucker, P. (2003), The New Society: The Anatomy of the Industrial Order. $3^{\text {rd }}$ edn. Harper Bros., New York. 
Edvardsson, B. (1997), Quality in New Service Development: Key concepts and a frame of reference, International Journal of Production Economics, Vol. 52, No 1-2, pp 31-46.

(2005), Service quality: beyond cognitive Assessment, Managing Service Quality, Vol. 15, No. 2, pp. 127-131.

Edvardsson, B. and Enquist, B. (2009), Values-based service for sustainable business Lessons from IKE $A$. Routledge, London.

(2006), Quality Improvement in Governmental Services-The Role of Change Pressure Exerted by the "Market", The TQM Magazine, Vol. 18, No.1, pp. 7-21.

(2002), The IKEA SAGA- How Service Culture Drives Service Strategy, The Service Industries Journal, Vol. 22, No. 4, pp.153-186.

Edvardsson, B., Enquist, B. and Hay, M. (2006), Values Based Service Brands: Narratives from IKEA, Managing Service Quality, Vol.16, No. 3, pp. 230-246

Edvardsson, B., Gustafsson, A., Johnson, M.D. and Sanden, B. (2000), New Service Development and Innovation in the New Economy, Studentlitteratur, Lund.

Edvardsson, B., Gustafsson, A. and Roos, I. (2005), Service portraits in service research - a critical review, International Journal of Service Industry Management, Vol. 16 No. 1, pp. 107-21

Ehrenfeld, J. R. (2005), The Roots of Sustainability, MIT Sloan Management Review, winter, Vol.46, No. 2, pp. 23-25.

Eisenhardt, K.M. (1989), Building Theories from Case Study Research, Academy of Management Review, Vol. 14, No. 4, pp. 532-550.

Eisenhardt, K.M. and Graebner, M.E. (2007), Theory building from cases: opportunities and challenges, Academy of Management Journal, Vol.50, No. 1, pp. 25-32.

Elkington, J. (2001), The chrysalis economy: how citizen CEOs and corporations can fuse values and value creation, Capstone Publishing, London.

(1998), Cannibals with forks: The triple bottom line of the 21st Century Business, Capstone Publishing, Oxford. 
Ellram, L.M., Tate, W. L. and Billington, C. (2004), Understanding and Managing the Services Supply Chain, The Journal of Supply Chain Management, Vol. 40, No. 4, pp.17-32

Enquist, B., Edvardsson, B., and Sebhatu, S. P. (2007), Values-based Service Quality for sustainable business, Managing Service Quality, Vol. 17, No. 4, pp.385-403.

(2008), Corporate Social Responsibility for Charity or for Service Business?, The Asian journal on Quality, Vol. 9, No. 1, pp.55-67.

Enquist, B., Johnsson, M and Skålén, P. (2006), Adoption of Corporate Social Responsibility - Incorporating a Stakeholder Perspective, Qualitative Research in Accounting \& Management, Vol. 3, No. 3, pp. 188-207

Enquist, B. and Sebhatu, S.P. (2006), "Walk the Talk" for Sustainable Citizenship - EPOPA as a potential Values-Based Sustainable Business Case?, Karlstad University working paper. Presented at GIMPA, Accra in Ghana November 2006 with the theme 'Is Corporate Citizenship Making a Difference?'

Epstein, E. (1987), The corporate social policy process: beyond business ethics, corporate social responsibility and corporate social responsiveness, California Management Review, Vol. 29 No.3, pp.99-114.

Epstein, M. J. (2008), Making Sustainability Work: Best practices in managing and measuring social and environmental impacts. Greenleaf, Sheffield.

Epstein, M. J. and Roy, M. J. (2003), Improving sustainability performance: specifying, implementing and measuring key principles, Journal of General Management, Vol. 29, No. 1, pp.15-31.

Fitch, H.G. (1976), Achieving corporate social responsibility, Academy of Management Review, Vol. 1, No., pp.38-46.

Freeman, R. E. (1994), The politics of stakeholder theory: Some future directions, Business Ethics Quarterly, Vol. 4, No. 4, pp. 409-421.

Friedman, M. (1962), Capitalism and freedom. University of Chicago Press, Chicago.

(1970), Social responsibility of business is to increase its profit, The New York Times Magazine, Vol. 13, pp.122-126. 
Friedman, T.L. (2008), Hot flat and crowded. Penguin Books Ltd, London.

(2006), The world is flat: a brief history of the globalized world in the twenty-first century. Penguin Books Ltd, London.

Gadamer, H. G. (1976), The historicity of understanding, in Connerton P. (ed.), Critical sociology, selected readings, Harmondsworth, pp.117-133.

(1994), Truth and Method, 2nd rev. edn. (Translation revised by Joel Weinsheimer and Donald G. Marshall (edtrs.)), Continuum, New York.

Garvin, David A. (1983), Quality on the Line, Harvard Business Review Vol. 61, No. 5, pp.64-75.

Ghauri P., Grønhaug K. and Kristianslund I. (1995), Research methods in business studies: A practical guide, Prentice Hall, New York.

Ghobadian, A., Speller, S. and Jones, M. (1994), Service quality concepts and models, International Journal of Quality \& Reliability Management, Vol.11, No. 9, pp. 43-66.

Gillberg, M. (1999), From green image to green practice: Normative action and selfregulation, diss. Dept. of Sociology, Lund University.

Grisvold, S. E. (1999), Citation analysis and journal impact factors - is the tail wagging the dog? Acta Anaesthesiologica Scandinavica, Vol.43, No.10, pp. 971 973.

Grant, C. (1991), Friedman fallacies, Journal of Business Ethics, Vol. 10, No. 12, pp.907-914.

Gray J. (2006), 'Minimizing Environmental Impacts of a Major Construction: The Oresund Link', Integrated Environmental Assessment and Management, Vol. 2, No.2, pp. 196-199.

Grönroos, C. (1984), Strategic management and marketing in the service sector. Chartwell-Bratt, Bromley, Kent.

Guay T., Jonathan P. D. and Graham S. (2004), Non-Governmental Organizations, Shareholder Activism, and Socially Responsible 
Investments: Ethical, Strategic, and Governance Implications, Journal of Business Ethics, Vol.52, No.1, pp. 125-139.

Gummesson, E. (2008), Total relationship marketing. 3 $3^{\text {rd }}$ edn., ButterworthHeinemann, Oxford.

(2007a), Exit services marketing - enter service marketing, Journal of Customer Behaviour, Vol. 6 No. 2, pp. 113-41.

(2007b), Case study research and network theory: Birds of a feather, Qualitative Research in Organizations and Management, Vol. 2 No. 3, pp. 226-48.

(2006), Many-to-Many marketing as grand theory: A Nordic school contribution, in Lusch, R. F and Vargo, S. L (eds.) (2006) The service dominant logic of marketing, M.E. Sharpe, New York.

(2000), Qualitative methods in management research. $2^{\text {nd }}$ edn., SAGE, Thousand Oaks, CA.

(1999), Total relationship marketing:[rethinking marketing management]: from 4Ps to 30Rs. Butterworth Heinemann, Oxford.

(1994), Green service quality, in Edvardsson, B. and Scheuing, E.E. (Eds), Proceedings from QUIS 3, Quality in services symposium, Karlstad, Sweden, June 1992, ISQA, New York.

Hamel, J., Dufour, S., and Fortin, D. (1993), Case study methods. Sage Publications, Newbury Park, CA.

Harrison, J. and Freeman, E. (1999), Stakeholders, social responsibility and performance: empirical evidence and theoretical perspectives, Academy of Management Journal, Vol. 42, No. 5, pp. 479-485

Hart, C. (2001), Doing a literature search: a comprehensive guide for the social sciences, SAGE, London.

Hart, S. (1997), Beyond greening: Strategies for a sustainable world, Harvard Business Review, Vol. 75, pp. 66-76. 
(2007), Capitalism at the crossroads: The unlimited opportunities in solving the world's most difficult Problems, 2 ${ }^{\text {nd }}$ edn., Wharton School Publishing, Upper Saddle River, NJ.

Hart, S. L., and Christensen, C. M., (2002), The great leap: driving innovation from the base of the pyramid, MIT Sloan Management Review, Vol. 44, No. 1, pp. 51-56.

Heal, G. (2005), Corporate social responsibility: An economic and financial framework, Geneva Papers, Vol. 30, No. 3, pp.387-409.

Heskett, J.L., Sasser, W.E. and Schlesinger, L.A. (1997), The service profit chain: How leading companies link profit and growth to loyalty, satisfaction, and value. Free Pr, New York.

Hirsch, E. Donald (1976), The Aims of Interpretation. University of Chicago Press, Chicago.

Hoffmann, M. (1999), Problems with Peirce's concept of abduction, in Foundations of science, Vol.4, No. 3, pp. 271-305

Hoffman, A. J. (2007), Carbon strategies: how leading companies are reducing their climate change footprint. University of Michigan Press, Ann Arbor.

Hoffman R. C. (2007), Corporate social responsibility in the 1920s: an institutional perspective, Journal of Management History, Vol. 13 No. 1, pp. 5573.

Johnson, M. (2007), Stakeholder dialogue for sustainable service, dissertation, Karlstad University Studies, Karlstad.

Jones T. M. (1980), Corporate social responsibility revisited, redefined, California Management Review, Vol. 22, No.2, pp. 59-67.

(1995), Instrumental stakeholder theory: a synthesis of ethics and economics, Academy of Management Review, Vol. 20 No.2, pp.404-37.

(1999), The institutional determinants of social responsibility, Journal of Business Ethics, Vol. 20, No. 2, pp.163-179.

Kandachar, P. and Halme, M. (Eds.) (2008) Sustainability challenges and solutions at the base-of-the-pyramid: Business, technology and the poor, Green Leaf Publishing, Sheffield. 
Kandachar, P. and Halme, M. (2007), Introduction, Greener Management International No.51, pp.3-17.

Kaplan, B. and Maxwell, J.A. (1994), Qualitative research methods for evaluating computer information systems, in Anderson, J.G. , Aydin, C.E. and Jay, S.J. (eds.), Evaluating health care information systems: Methods and applications, Sage, Thousand Oaks, CA: 45-68

Karnani, A. (2007a), Fortune at the bottom of the pyramid: a mirage. California Management Review, Vol. 49, No. 4, pp. 90-111

(2007b), Employment, not microcredit, is the solution, Ross School of Business Working Paper No. 1065, University of Michigan.

Kemp, P. (2005). Världsmedborgaren: politisk och pedagogisk filosofi för det 21 århundradet. Daidalos, Göteborg.

Kim, Y. P., Lee, S.H., and Yun, D.-G. (2004), Integrating current and competitive service quality level analyses for service quality improvement programs, Managing Service Quality, Vol. 14 No.4, pp.288-96

Kotler, P. and Lee, N. (2005), Corporate social responsibility: Doing the most good for your company and your cause. Wiley, Hoboken, NJ.

Kuhn T. S., (1996), The structure of scientific revolutions, $3^{\text {rd }}$ edn., University of Chicago Press, Chicago, Ill.

Laczniak, G. R. (2006), Some societal and ethical dimensions of the servicedominant logic perspective of marketing, in Lusch, R. F and Vargo, S. L (eds.) The service dominant logic of marketing, M.E. Sharpe, New York.

Laszlo, C. (2008), Sustainable value: How the world's leading companies are doing well by doing good, Island Press, Washington DC.

(2003), The sustainable company: How to create lasting value through social and environmental performance, Island Press, Washington DC.

Levitt, T. (1958), The dangers of social responsibility, Harvard Business Review, Vol.36, No. 5, pp.41-50.

Lindahl, C. (2005), Wealth of the poor: eliminating poverty through market and private sector development. SIDA, Stockholm. 
London, T. (2007), A base-of-the-pyramid perspective on poverty alleviation, William Davidson Institute, Working Paper, University of Michigan.

London, T. and Hart, S.L. (2004), Reinventing strategies for emerging markets: Beyond the transnational model. Journal of International Business Studies, Vol. 35, No. 5, pp. 350-371.

Lovelock, C.H. and Gummesson, E. (2004), Whither services marketing? In search of a new paradigm and fresh perspectives, Journal of Service Research, Vol. 6 No. 5, pp. 20-41.

Lusch, R. F. and Vargo, S. L. (2008), The Service-Dominant Mindset, Service Science, Management and Engineering, pp. 89-96

Lusch, Robert F. and Vargo, S. L. (2006), Service-Dominant Logic as a Foundation for Building a General Theory, in Lusch R. F. and Vargo S. L. (eds.), The Service-Dominant Logic of Marketing: Dialog, Debate, and Directions, Armonk, M.E. Sharpe, pp. 406-420.

Lusch, Robert F., Vargo, S. L. and Malter, A. J. (2006), Marketing as ServiceExchange: Taking a Leadership Role in Global Marketing Management, Organizational Dynamics, Vol. 35, No.3, pp. 264-278.

Lusch, Robert F., Vargo, S. L. and Wessels, G. (2008), Toward a Conceptual Foundation for Service Science: Contributions from Service-Dominant Logic, IBM Systems Journal, Vol. 47, No. 1, pp. 5-14.

Marens, R. (2008), The hollowing out of corporate social responsibility: Abandoning a tradition in an age of declining hegemony, McGeorge Law Review, Vol. 39 No. 3, pp. 851-876.

Margolis, J. D. and Walsh, J. P. (2003), Misery loves companies: Rethinking social initiatives by business, Administrative Science Quarterly, Vol. 48, No.2, pp. 268-305.

Maxwell, J. A. (2005), Qualitative research design: An interactive approach, 2. ed. Sage, Thousand Oaks, CA.

McWilliams, A. and Siegel, D. (2001), Corporate social responsibility: A theory of the firm perspective, The Academy of Management Review, Vol. 26 No. 1, pp. 117-127. 
Merriam, S. B. (1988), Case study research in education: A qualitative approach, Jossey-Bass, San Francisco, CA.

(1985), The Case Study in Educational Research: A Review of Selected Literature, Journal of Educational Thought, Vol. 19, No. 3, pp. 204-17.

Micheletti, M. (2003), Political Virtue and Shopping. Palgrave, New York.

Micheletti, M. and Stolle D., (2007), 'Mobilizing Consumers to Take Responsibility for Global Social Justice', The ANNALS of the American Academy of Political and Social Science, Vol. 611, No.1, pp. 157-175

Miller, D. (1982), Evolution and revolution: a quantum view of structural change in organizations', Journal of Management Studies, Vol.19, No. 2, pp. 131-51.

Mintzer, I. M. (1992), Insurance against the heat trap: Estimating the costs of reducing the risks, in Pearman, G.I. (ed.), Limiting the greenhouse effect: Options for controlling atmospheric CO2 accumulation, John Wiley, New York.

Moon, J. (2002), Corporate social responsibility: An overview, The international directory of corporate philanthropy, Europa Publications, London, pp. 3-14.

Morgan, N. (2001), How to overcome "change fatigue", Harvard Management Update, Vol. 6, No. 7, pp. 1-3.

Myers, M. D. (1997), Qualitative research in information systems, MIS Quarterly, Vol. 21, No. 2, pp. 241-242.

Myerson, D.E. (2001), Radical change: The quiet way, Harvard Business Review, Vol. 79, No. 9, pp. 92-100.

Neely, A.D. (1998), Measuring business performance: Why, what and how. Economist, London.

Normann, R. (2001), Reframing business: When the map changes the landscape. Wiley, Chichester.

Narver, J. C. (1971), Rational management responses to external effects. Academy of Management Journal, Vol.14, No.1, pp. 99-115.

Oliver, C. (1991), Strategic responses to institutional processes, Academy of Management Review, Vol.16, No. 1, pp. 145-179. 
Odman, P.J. (1985), Hermeneutics, in Husen, T. and Postlethwaite, T. (eds.), The International Encyclopedia of Education, Pergamon, Oxford, pp.2162-2169.

O'Sullivan M. (2009), What opportunity is knocking? Regulating corporate governance in the United States, in Balleisen, E. and Moss, D. (eds.) Government and markets: Toward a new theory of regulation, Cambridge University Press, Cambridge, pp.335-362.

Palmisano S. J. (2006), The globally integrated enterprise, Foreign affairs, Vol. 85, No. 3, pp.127-136.

Parasuraman, A., Zeithaml, V.A. and Berry, L.L. (1988), SERVQUAL: A multi-item scale for measuring consumer perceptions of service quality, Journal of Retailing Vol. 64, No. 1, pp.12-40.

Pentland, B.T. (1999), Building process theory with narrative: From description to explanation, The Academy of Management Review, Vol. 24, No. 4, pp. 711724.

Peet, R. and Hartwick, E. (2009), Theories of development: Contentions, arguments, alternatives. The Guilford Press, New York, NY.

Poncelet E. (2003), Resisting corporate citizenship: Business-NGO relations in multi-stakeholder environmental partnerships, Journal of Corporate Citizenship, Vol.3, No.9, pp. 97-115.

Ponte, S. (2004), Standards and sustainability in the coffee sector: A global value chain approach, International institute for sustainable development, Winnipeg, Canada.

Porter, M. (2008), On competition: Updated and expanded edition. Harvard Business School, Boston, Mass.

Porter, M. E., and Kramer, M. R. (2002), The competitive advantage of corporate philanthropy, Harvard Business Review, Vol. 80, No. 12, pp.56-69.

Porter, M. E., and Kramer, M. C. (2006), Strategy and society: the link between competitive advantage and corporate social responsibility, Harvard Business Review, Vol. 84, No. 12, pp.78-92.

Post, J., Preston, L. and Sachs, S. (2002), Redefining the corporation: stakeholder management and organizational wealth, Stanford University press, Stanford, Ca. 
Prahalad C.K. (2005), The fortune at the bottom of the pyramid: Eradicating poverty through profits, Wharton School Publ., Philadelphia, Pa.

Prahalad, C.K. and Hart, S.L. (2002), The fortune at the bottom of the pyramid, Strategy and Business, Vol. 26, pp.2-14.

Prahalad, C.K., and Ramaswamy V. (2004), The future of competition - Co-creating unique value with customers. Harvard Business School Publishing, Boston, Mass.

Preston, L.E. (1975), Corporation and society: the search for a paradigm, Journal of Economic Literature, Vol. 13, No. 2, pp.434-453.

Prieto-Carrón, M., Lund-Thomsen P., Chan A., Muro A. and Bhushan C. (2006), Critical perspectives on CSR and development: what we know, what we don't know, and what we need to know, International Affairs, Vol. 82, No. 5, pp.977-987.

Pruzan, P. (1998), From Control to Values-Based Management and Accountability, Journal of Business Ethics, Vol. 17, No. 13, pp. 1379 - 1394.

Rae, S.B. and Wong, K.L. (Eds.), (2004), Beyond integrity: A Judeo-Christian approach to business ethics, $2^{\text {nd }}$ edn. Zondervan, Grand Rapids, MI.

Reich, R.B. (2008), The case against corporate social responsibility, Goldman School of Public Policy Working Paper No. GSPP08-00. Available at SSRN: http://ssrn.com/abstract=1213129 (February, 2009).

Ricart, J. E., Enright, M. J., Ghemawat, P., Hart, S. L., and Khanna, T. (2004), New frontiers in international strategy, Journal of International Business Studies, Vol. 35, No. 3, pp. 175-200.

Ricoeur, P. (1974), The conflict of interpretations: Essays in hermeneutics, Northwestern University Press, Evanston.

(1976), Interpretation Theory: Discourse and the Surplus of Meaning, Christian University Press, Fort Worth Texas.

(1981), Hermeneutics and the human sciences: essays on language, action and interpretation, Cambridge University Press, Cambridge. 
(1991), From text to action, II. Translated by Blamey $\mathrm{K}$ and Thompson J., North-western University Press, Evanston.

Roome, N. J. (1998), Industrial management; Social responsibility of business; Environmental aspects, in Roome, N.J. (Ed.) Sustainability strategies for industry: The future of corporate practice, Island Press, Washington, DC.

Sanchez, P., Ricart, J. E., and Rodríguez, M. Á. (2007), Influential factors in becoming socially embedded in low-income markets, Greener Management International, Vol. 51, pp. 19-38.

Sandberg, J. and Targama, A. (1998), Ledning och förståelse. Ett kompetensperspektiv på organisationer. Studentlitteratur, Lund.

Schmidheiny, S. with Business Council for Sustainable Development (1992), Changing Course: A global business perspective on development and the environment, The MIT Press, Cambridge, MA

Schneider, B. and White, S.S (2004), Service quality: Research perspectives, SAGE, Thousand Oaks, CA.

Sebhatu, S. P., (2008), The challenges and opportunities in creating sustainable shared values at the base of the pyramid - Cases from sub-Saharan Africa, in Kandachar, P. and Halme, M. (Eds.) Sustainability challenges and solutions at the base-of-the-pyramid: Business, technology and the poor, Green Leaf Publishing, Sheffield, pp.146-162.

Sebhatu, S. P., and Enquist B., (2007), ISO 14001 as a driving force for sustainable development and value creation, The TQM Magazine, Vol. 19, No. 5, pp.468-482.

Sen, A. (1999), Development as Freedom. Knopf, New York, NY.

Sethi, S.P. (1975), Dimensions of corporate social performance: An analytic framework, California management Review, Vol.17, No. 3, pp.58-64.

Shaw, C. and Ivens, J. (2002), Building great customer experiences. Palgrave, London.

Simanis, E., and Hart S. (2006), Expanding possibilities at the base of the pyramid, Innovations, Vol. 1, No.1, pp.43-51.

Sjöström E. (2008), Shareholder activism for corporate social responsibility: What do we know?, Sustainable Development, Vol.16, No. 3, pp.141-154. 
Stiglitz, J.E. (2007), Making globalization work. W.W. Norton, New York, NY.

Sureshchandar, G.S., Rajendran, C. and Anantharaman, R. N. (2002), The relationship between service quality and customer satisfaction - a factor specific approach, Journal of Services Marketing, Vol. 16, No. 4, pp. 363-379.

Taylor, C. (1976), Hermeneutics and politics; in Connerton, P. (ed.), Critical sociology, selected readings, Harmondsworth, pp.153-193.

Tead, O. and Metcalf, H. (1933), Personnel Administration: Its Principles and Practice, 2nd ed., McGraw-Hill, New York, NY.

Teegen, H., Doh, J.P. and Vachani, S. (2004), The importance of nongovernmental organizations (NGOs) in global governance and value creation: an international business research agenda, Journal of International Business Studies, Vol. 35, No. 6, pp.463-83.

Vargo, S. L. (2008), Customer Integration and Value Creation: Paradigmatic Traps and Perspectives, Journal of Service Research Vol.11, No. 2, pp. 211-215.

Vargo, S. L. (2007), Paradigms, Pluralisms, and Peripheries: On the Assessment of the S-D Logic, Australasian Marketing Journal, Vol. 15, No.1, pp. 105-108.

Vargo, S. L. and Lusch, R. F. (2008a), Service-dominant logic: Continuing the evolution, Journal of the Academy of Marketing Science, Vol. 36, No. 1, pp. 1-10.

(2008b), Why "service"?, Journal of the Academy of Marketing Science, Vol. 36, pp. 25-38.

(2006), Service-Dominant Logic: What it is, What it is not, What it might be, in Lusch, R. F. and Vargo S. L. (eds), The Service-Dominant Logic of Marketing: Dialog, Debate, and Directions, Armonk, M.E. Sharpe, pp. 43-56.

(2004), Evolving to a new dominant logic of marketing, Journal of Marketing, Vol. 68, No. 1, pp.1-17.

Vargo, S. L., Lusch, R. F. and Morgan F. W. (2006), Historical Perspectives on Service-Dominant Logic, in Lusch, R. F. and Vargo S. L. (eds), The Service- 
Dominant Logic of Marketing: Dialog, Debate, and Directions, Armonk, M.E. Sharpe, pp. 29-42.

Vargo, S. L., Maglio, P. P. and Akaka. M. A. (2008), On value and value cocreation: A service systems and service logic perspective, European Management Journal, Vol. 26, pp.145-152.

Visser W. (2006), Revisiting Carroll's CSR pyramid, in Huniche, M. and Rahbek Pedersen, E. (Eds.) Corporate citizenship in developing countries: new partnership perspectives, Copenhagen Business School Press, Copenhagen, pp.29-56.

Vogel, D. (2005), The market for virtue: The potential and limits of corporate social responsibility. The Brookings Institution, Washington D.C.

Waddock, S. (2008), The Difference Makers: How Social and Institutional Entrepreneurs Created the Corporate Responsibility Movement, Green Leaf Publishing, Sheffield.

(2006), Leading corporate citizens: Vision, values, value added. McGrawHill Higher Education, New York.

(2004), Creating corporate accountability foundational principles to make corporate citizenship real, Journal of Business Ethics, Vol. 50, No. 4, pp.313-327.

Waddock, S. and Bodwell, C. (2007), Total responsibility management: The manual. Greenleaf Publishing, Sheffield.

(2004), Managing responsibility: What can be learned from the quality movement?, California Management Review, Vol. 47, No.1, pp.25-37.

Waygood S. and Wehrmeyer W. (2003), A critical assessment of how nongovernmental organizations use the capital markets to achieve their aims: a UK study, Business Strategy and the Environment, Vol. 12, No.6, pp.372-385.

Wheeler D., Colbert B. and Freeman R.E. (2003), Focusing on value: Reconciling corporate social responsibility, sustainability and a stakeholder approach in a network world, Journal of General Management, Vol.28, No.3, pp. $1-29$. 
Williams, C. A. and Aguilera, R.V. (2008), Corporate social responsibility in a comparative perspective, in Crane, A. (Ed.) The Oxford Handbook of Corporate Social Responsibility. Oxford University Press, Oxford.

Winston M. (2002), NGO Strategies for Promoting Corporate Social Responsibility, Ethics \& International Affairs, Vol. 16, No. 2, pp. 71-87.

World Business Council for Sustainable Development (2004), Doing business with the poor: A field guide, WBCSD, Geneva.

(1996), Eco-efficient leadership: for improved economic and environmental performance, WBCSD, Geneva, also available at http://www.wbcsd.org Eco-efficiency core publications (March 2005).

World Commission on Environment Development (1987), Our common future, Oxford University Press, Oxford.

Xueming, L. and Bhattacharya C.B. (2006), Corporate social responsibility, customer satisfaction and market value, Journal of Marketing, Vol. 70, No.4, pp. 1-18.

Yin, R.K. (2003), Case study research: Design and methods, 3 $3^{\text {rd }}$ edn. Sage Publications, Thousand Oaks, CA.

(1994), Case study research: Design and methods, 2nd edn. SAGE, Newbury Park, CA.

Zadek, S., (2004), The path to corporate responsibility, Harvard Business Review, Vol. 82 No.12, pp $125-133$.

(2001), The civil corporation: The new economy of corporate citizenship, Earthscan, London.

Zeithaml, V.A. (2000), Service quality, profitability, and the economic worth of customers: What we know and what we need to learn, Journal of the Academy of Marketing Science, Vol. 28, No. 1, pp. 67-85. 
